\title{
Fac and Mer dppe-substituted Fischer Carbene complexes of chromium: X-ray, DFT and electrochemical study
}

Marilé Landman, ${ }^{\mathrm{a}, *}$ Renyuan Liu, ${ }^{\mathrm{b}}$ Roan Fraser, ${ }^{\mathrm{a}}$ Petrus H. van Rooyen ${ }^{\mathrm{a}}$ and Jeanet Conradie, ${ }^{\mathrm{b},{ }^{*} *}$

${ }^{\text {a }}$ Chemistry Department, University of Pretoria, Private Bag X20, Hatfield, 0028, South Africa. Tel: 27-12-4202527 Fax: 27-12-4204687

b Department of Chemistry, PO Box 339, University of the Free State, Bloemfontein, 9300, South Africa, Tel: 27-51-4012194, Fax: 27-51-4446384.

c Center for Theoretical and Computational Chemistry (CTCC), University of Tromsø, N-9037 Tromsø, Norway.

* Contact author details:

Name: Marilé Landman Tel: ++27-12-4202527 Fax: ++27-12-4204687, email: marile.landman@up.ac.za

Name: Jeanet Conradie, Tel: ++27-51-4012194, Fax: ++27-51-4446384, email: conradj@ufs.ac.za

Keywords: Fischer dppe complexes, Electrochemistry, DFT calculations

\section{Table of content diagram}

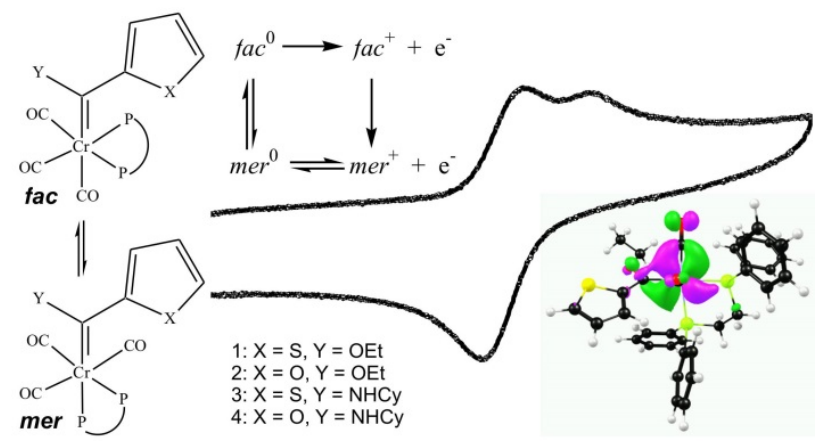

\section{Table of content briefs}

X-ray, DFT and electrochemical study of isomeric fac and mer Cr Fischer carbenes 


\section{Fac and Mer dppe-substituted Fischer carbene complexes of chromium: X-ray, DFT and electrochemical study}

Marilé Landman, ${ }^{\mathrm{a}, *}$ Renyuan Liu, ${ }^{\mathrm{b}}$ Roan Fraser, ${ }^{\mathrm{a}}$ Petrus H. van Rooyen ${ }^{\mathrm{a}}$ and Jeanet Conradie, ${ }^{\mathrm{b}, \mathrm{c}_{*}}$

${ }^{a}$ Chemistry Department, University of Pretoria, Private Bag X20, Hatfield, 0028, South Africa. Tel: 27-12-4202527 Fax: 27-12-4204687

${ }^{\mathrm{b}}$ Department of Chemistry, PO Box 339, University of the Free State, Bloemfontein, 9300, South Africa, Tel: 27-51-4012194, Fax: 27-51-4446384.

c Center for Theoretical and Computational Chemistry (CTCC), University of Tromsø, N-9037 Tromsø, Norway.

\section{Abstract}

X-ray crystallography data, DFT calculations and cyclic voltammograms in synergy shed light on the $m e r \leftrightarrow f a c$ isomerization process of $\mathrm{Cr}$ carbenes of the type $\left[(\mathrm{CO})_{3}(\mathrm{dppe}) \mathrm{Cr}=\mathrm{C}(\mathrm{X}) \mathrm{R}\right]$ with $\mathrm{R}=$ 2-thienyl or 2-furyl and $\mathrm{X}=\mathrm{OEt}$ or $\mathrm{NHCy}$, both in the neutral and oxidized states. Cyclohexylamino-containing complexes are easier oxidized and reduced than ethoxy-containing complexes. Dppe-containing complexes are considerably easier oxidized and reduced than nonphosphine containing $\mathrm{Cr}$-Fischer carbene complexes of the type $\left[(\mathrm{CO})_{5} \mathrm{Cr}=\mathrm{C}(\mathrm{X}) \mathrm{R}\right]$ with $\mathrm{X}=\mathrm{OEt}$, $\mathrm{NHBu}, \mathrm{NMe}_{2}$ or $\mathrm{N}\left(\mathrm{CH}_{2} \mathrm{Ph}\right)_{2}$ and $\mathrm{R}=$ phenyl, thienyl, furyl, NMe-pyrrole, $\mathrm{H}$ or Me. The oxidation and reduction potential of the $\left[(\mathrm{CO})_{3}(\mathrm{dppe}) \mathrm{Cr}=\mathrm{C}(\mathrm{X}) \mathrm{R}\right]$ complexes are not very sensitive to the influence of the heteroarene rings 2-thienyl or 2-furyl.

\section{Introduction}

Modification of the ligand sphere of carbonyl carbene complexes, using phosphines as alternatives to carbonyl ligands, was studied not long after the discovery of the first metal carbene complex [1,2,3]. It was noted by Fischer that these ligands allowed the complexes higher stability in air than their carbonyl analogues [3]. The synthesis of monophosphine-containing carbene complexes is normally promoted through thermal or photochemical processes [4] and was extended by the Fischer group to include both different metals and different carbene substituents [5]. A specific application for phosphine-containing carbene complexes was found in the synthesis and isolation of optically active cyclopropane from a reaction employing [(-)(R)- 
methylphenylpropylphosphine] (phenylmethoxycarbene) [6]. The first stable chiral Mo- and Cr Fischer carbene complexes containing a chiral biphosphite ligand LL was synthesized and characterized by Barluenga in 2002 [7]. It was shown that the $f a c-\left[\left(\eta^{2}-\mathrm{LL}\right)(\mathrm{CO}){ }_{3} \mathrm{Mo}=\mathrm{C}(\mathrm{OMe}) \mathrm{Ph}\right]$ (LL = trans-1,2-bis[bis(2,2,2-trifluoro-1-(trifluoromethyl)ethoxy)phosphinoxy]cyclopentane) complex can thermally isomerize to form the corresponding mer complex. Extensive electrochemical and EPR spectroscopic studies have been done by Bond, Colton, and co-workers [8] on the fac (cis) and mer (trans) isomers of tricarbonyl-chromium(I) phosphine, phosphite and bidentate phosphine complexes. They showed for example that while fac-[Cr(CO) $\left.)_{3} \mathrm{~L}_{3}\right](\mathrm{L}=$ phosphine, phosphite) is stable in the 18-electron $\operatorname{Cr}(0)$ state, the 17-electron $\operatorname{Cr}(\mathrm{I})$ complex rapidly rearranges to the meridional conformation: fac- $\left[\mathrm{Cr}(\mathrm{CO})_{3} \mathrm{~L}_{3}\right]^{+} \rightarrow \operatorname{mer}-\left[\mathrm{Cr}(\mathrm{CO})_{3} \mathrm{~L}_{3}\right]^{+}$. They also found that for the sterically strained 18-electron $\left[\mathrm{Cr}(\mathrm{CO})_{3}\left(\eta^{3}-\mathrm{P}_{2} \mathrm{P}^{\prime}\right)\right]$ containing a tridentate phosphine $\left(\mathrm{P}_{2} \mathrm{P}^{\prime}=\mathrm{Ph}_{2} \mathrm{PCH}_{2} \mathrm{CH}_{2} \mathrm{P}(\mathrm{Ph}) \mathrm{CH}_{2} \mathrm{CH}_{2} \mathrm{PPh}_{2}\right)$, the 17-electron fac $^{+}$and mer $^{+}$isomers are of comparable stability. Rieger and Rieger [9] found that tricarbonyl Cr(I) complexes with bidentate phosphine and arsine ligands all behave very similarly. The one-electron chemical oxidation of mer$\left[\mathrm{Cr}(\mathrm{CO})_{3}\left(\eta^{1}-\mathrm{LL}\right)\left(\eta^{2}-\mathrm{LL}\right)\right](\mathrm{LL}=\mathrm{dppm}$, dmpe, arphos, dppbz) results in the formation of the corresponding $\mathrm{mer}^{+}$complex, while oxidation of $f a c-\left[\mathrm{Cr}(\mathrm{CO})_{3}\left(\eta^{1}-\mathrm{LL}\right)\left(\eta^{2}-\mathrm{LL}\right)\right]$ results in the expected rapid rearrangement to the $\mathrm{mer}^{+}$isomer. In both cases the $\mathrm{mer}^{+}$isomer is stable if kept airfree and in the dark.

In this study we present the synthesis of four novel Fischer carbene complexes of the type $\left[(\mathrm{CO})_{3}(\mathrm{dppe}) \mathrm{Cr}=\mathrm{C}(\mathrm{X}) \mathrm{R}\right]$ with $\mathrm{R}=$ 2-thienyl or 2-furyl and $\mathrm{X}=\mathrm{OEt}$ or NHCy and dppe $=1$,2bis(diphenylphosphino)ethane, (1-4), see Scheme 1. The fac isomers of two and the mer isomers of all four complexes were characterized in the solid state. Additionally, a cyclic voltammetry study of these novel Fischer carbenes is presented, the first electrochemical study on the behaviour of facand mer-substituted phosphine carbene complexes. A DFT computational chemistry study allows for a better understanding of the oxidation and reduction processes, observed at different potential for the fac- and the mer isomers.

\section{Material and methods}

\section{General}

Infrared spectra were recorded on a Perkin-Elmer Spectrum RXI FT-IR spectrophotometer using $\mathrm{KBr}$ pellets. Nuclear magnetic resonance spectra were recorded on a Brüker AC-300 spectrometer. FAB mass spectra were recorded on both an Agilent 2890 and an Agilent 6850 gas chromatograph equipped with an Agilent 7683 auto-injector, HP-5 capillary column (30 m $\times 320$ $\mu \mathrm{m} \times 0.25 \mu \mathrm{m}$ ) and a flame ionisation detector (FID). CHN elemental analyses were done on a 
Thermo Scientific Flash 2000 CHNS Elemental Analyser and has an accuracy of $\pm 0.3 \%$ (absolute). All the solvents were dried under an inert atmosphere of nitrogen gas following the conventional laboratory methods prior to use [10]. Chromatographic separations and purification were performed using nitrogen gas saturated kieselgel (0.063-0.200 mm). All compounds were synthesised and characterized under an inert atmosphere of argon or nitrogen gas, using standard Schlenk tube methods unless otherwise specified [11]. Solid reagents used in preparations (Merck, Aldrich and Fluka) were used without further purification. Thiophene was purified as described in literature, prior to use [12]. Triethyloxonium tetrafluoroborate [13], [Cr(CO) ${ }_{5} \mathrm{C}(\mathrm{OEt})(2-$ thienyl)] [28] (5) and $\left[\mathrm{Cr}(\mathrm{CO})_{5} \mathrm{C}(\mathrm{OEt})(2\right.$-furyl $\left.)\right][28,29]$ (6) were prepared according to known literature procedures.

\section{Synthesis}

1,2-Bis(diphenylphosphino)ethane chelated ethoxycarbene complexes (1 and 2)

An oven-dried $50 \mathrm{ml}$ round-bottomed flask was filled with inert argon gas and $20 \mathrm{ml}$ of dried toluene was added as solvent. [(CO) $)_{5} \mathrm{Cr}=\mathrm{C}(\mathrm{OEt}) \mathrm{R}$ ], with $\mathrm{R}=$ 2-thienyl (5) or 2-furyl (6) (1.0 mmol) was dissolved in toluene and 1,2-bis(diphenylphosphino)ethane (1.0 mmol, $0.40 \mathrm{~g}$ ) was added in a single portion. The reaction mixture was allowed to reflux at $90{ }^{\circ} \mathrm{C}$ until the reaction had proceeded to completion. The solvent was removed in vacuo. The mixture was purified on a silica gel column by eluting first with hexane and secondly with a hexane:DCM (8:2) mixture. The product was recovered from the column with a hexane:DCM mixture (8:2) as eluent. Product fraction: Redbrown (chelated monocarbene complex 1 or 2).

Carbene quantities reacted:

Complex 5 (1.0 mmol, 0.33 g) for complex 1

Complex 6 (1.0 mmol, $0.32 \mathrm{~g}$ ) for complex 2

Products:

Complex 1: Yield = 65\%; $\mathrm{NMR}{ }^{1} \mathrm{H}\left(\mathrm{CD}_{3} \mathrm{CN}, \delta(\mathrm{ppm}), \mathrm{J}(\mathrm{Hz})\right): 7.56(\mathrm{dd}, \mathrm{J}=3.9,0.8 \mathrm{~Hz}, 1 \mathrm{H}, \mathrm{H} 8)$, 7.49 (d, J = 5.0 Hz, 1H, H10), 6.96 (dd, J = 5.0, 3.9 Hz, 1H, H9), 7.33-7.49 (m, 16H, o-Ph, m-Ph), 7.68-7.74 (m, 4H, p-Ph), 4.48 (q, J = 7.0 Hz, 2H, CH $), 2.76-2.97$ (m, 2H, PCH17), 2.56-2.71 (m, 2H, PCH18), 1.20 (t, J = 7.0 Hz, 3H, $\left.\mathrm{CH}_{3}\right) .{ }^{13} \mathrm{C}$ NMR ( $\left.\mathrm{CD}_{2} \mathrm{Cl}_{2}, \mathrm{ppm}\right): 318.8$ (C6), 235.0 (CO), 227.0 (CO), 225.3 (CO), 157.3 (C7), 144.6 (C8), 141.8 (C10), 125.5 (C9), 138.0, 132.7, 131.6, $130.8(\mathrm{Ph}), 72.2\left(\mathrm{CH}_{2}\right) 29.7$ (PC17), 27.7 (PC18), $15.4\left(\mathrm{CH}_{3}\right) \cdot{ }^{31} \mathrm{P}\left(\left(\mathrm{CD}_{3}\right)_{2} \mathrm{CO}, \mathrm{ppm}\right): 82.8\left(\mathrm{~J}_{\mathrm{PP}}=\right.$ $4.2 \mathrm{~Hz}), 77.9\left(\mathrm{~J}_{\mathrm{PP}}=2.7 \mathrm{~Hz}\right)($ mer $), 81.4$ (fac). IR $\left(\mathrm{cm}^{-1}\right): 2008 \mathrm{vw}, 1953 \mathrm{w}, 1930 \mathrm{w}, 1866 \mathrm{~s}$ (mer) $2005 \mathrm{vw}, 1862$ s, 1840 s (fac). - MS (FAB): m/z [M] 676, [M] - (CO) 649, [M] - 2(CO) 618, 
$[\mathrm{M}]^{+}$- 3(CO) 592, [M] - 3(CO), OEt 547. - Anal. Calc. for $\mathrm{C}_{36} \mathrm{H}_{32} \mathrm{O}_{4} \mathrm{P}_{2} \mathrm{~S}_{1} \mathrm{Cr}_{1}$ : C, 64.09; H, 4.78. Found: C, 63.53; H, 4.82.

Complex 2: Yield = 63\%; $\mathrm{NMR}{ }^{1} \mathrm{H}\left(\left(\mathrm{CD}_{3}\right)_{2} \mathrm{CO}, \delta(\mathrm{ppm}), \mathrm{J}(\mathrm{Hz})\right): 7.66(\mathrm{~d}, \mathrm{~J}=1.7 \mathrm{~Hz}, 1 \mathrm{H}, \mathrm{H} 10), 6.54$ (d, J = 3.4 Hz, 1H, H8), 6.41 (dd, J = 3.4, 1.7 Hz, 1H, H9), 7.30-7.46 (m, 16H, o-Ph, m-Ph), 7.677.78 (m, 4H, p-Ph), 4.60 (q, J = 7.0 Hz, 2H, $\mathrm{CH}_{2}$ ), 2.79-2.90 (m, 2H, PCH17), 2.58-2.74 (m, 2H,

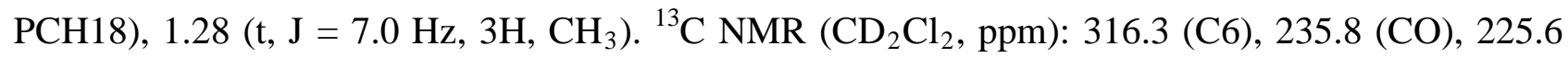
(CO), 220.1 (CO), 164.3 (C7), 146.1 (C10), 112.5 (C8), 111.8 (C9), 138.7, 132.7, 131.3, 130.6 (Ph), $73.7\left(\mathrm{CH}_{2}\right) 30.7$ (PC17), 28.4 (PC18, $15.6\left(\mathrm{CH}_{3}\right) .{ }^{31} \mathrm{P}\left(\left(\mathrm{CD}_{3}\right)_{2} \mathrm{CO}, \mathrm{ppm}\right): 82.1\left(\mathrm{~J}_{\mathrm{PP}}=4.4 \mathrm{~Hz}\right)$, $77.4\left(\mathrm{~J}_{\mathrm{PP}}=3.7 \mathrm{~Hz}\right)(\mathrm{mer}), 81.8(\mathrm{fac}) . \mathrm{IR}\left(\mathrm{cm}^{-1}\right): 2008 \mathrm{vw}, 1952 \mathrm{w}, 1923 \mathrm{w}, 1862 \mathrm{~s}, 1841 \mathrm{~s}$ (mer) 2007 vw, 1863 s, 1837 s (fac). - MS (FAB): m/z [M] 660, [M] $]^{+}$- (CO) 632, [M] - 2(CO) 604, $[\mathrm{M}]^{+}-3(\mathrm{CO})$ 576, [M] $]^{+}$- 3(CO), OEt 531. Anal Calc. for $\mathrm{C}_{36} \mathrm{H}_{32} \mathrm{O}_{5} \mathrm{P}_{2} \mathrm{Cr}_{1}$ : C, 65.65; H, 4.90. Found: C, 66.26; H, 5.01 .

1,2-Bis(diphenylphosphino)ethane chelated aminocarbene complexes (3 and 4)

An oven-dried Schlenk flask was filled with inert argon gas and $20 \mathrm{ml}$ of dried dichloromethane was added. [(CO) $\left.{ }_{5} \mathrm{Cr}=\mathrm{C}(\mathrm{OEt}) \mathrm{R}\right]$, with $\mathrm{R}=2$-thienyl (5) or 2-furyl (6) (1.0 mmol) was dissolved in the DCM and cyclohexylamine (1.0 mmol, $0.10 \mathrm{~g})$ added in a single portion. The reaction mixture was stirred until a yellow product was obtained. The solvent was removed, the product re-dissolved in toluene and dppe (1.0 mmol, $0.40 \mathrm{~g})$ added in a single portion. The reaction mixture was refluxed at $90{ }^{\circ} \mathrm{C}$ until all the yellow aminocarbene had been converted to a brown-orange product. The solvent was removed again in vacuo and the mixture transferred to a column. The products were purified with silica gel column chromatography and both the aminocarbene starting material and the chelated aminocarbene product were obtained. Separation was achieved by first eluting with hexane, thereafter with a hexane:DCM (1:1) mixture and finally with dried THF. Product fractions: Yellow (pentacarbonyl aminocarbene complex A or B); Brown-orange (chelated aminocarbene complex 3 or $\mathbf{4})$.

Carbene quantities reacted:

Complex 5 (1.0 mmol, $0.33 \mathrm{~g}$ ) for complex 3

Complex 6 (1.0 mmol, $0.32 \mathrm{~g}$ ) for complex 4

Products:

Complex 3: Yield = 67\%; NMR ${ }^{1} \mathrm{H}\left(\mathrm{CD}_{2} \mathrm{Cl}_{2}, \delta(\mathrm{ppm}), \mathrm{J}(\mathrm{Hz})\right): 8.40(\mathrm{~s}, 1 \mathrm{H}, \mathrm{NH}), 7.46(\mathrm{dd}, \mathrm{J}=3.7$, $1.2 \mathrm{~Hz}, 1 \mathrm{H}, \mathrm{H8}$ ), 7.42 (dd, J = 5.0, 1.1 Hz, 1H, H10), 7.03 (dd, J = 5.0, 3.7 Hz, 1H, H9), 7.20-7.40, 7.55-7.70 (m, 20H, Ph), 3.93 (m, 1H, H11), 2.85-2.96 (m, 2H, PCH17), 2.53-2.70 (m, 2H, PCH18), 1.20-2.10 (m, H12-H14). ${ }^{13} \mathrm{C}$ NMR (CD $\left.2 \mathrm{Cl}_{2}, \mathrm{ppm}\right): 277.7$ (C6), 234.4 (CO), 229.0 (CO), 220.1 
(CO), 150.6 (C7), 126.1 (C10), 123.0 (C8), 119.2 (C9), 138.0, 132.7, 131.1, 129.2 (Ph), 58.1 (C11), 30.3 (C12), 25.6 (C14), 25.0 (C13), 33.1 (PC17), 31.7 (PC18). ${ }^{31} \mathrm{P}$ ((CD $\left.)_{2} \mathrm{CO}, \mathrm{ppm}\right): 87.7,78.9$ (mer), 77.5 (fac). IR (cm ${ }^{-1}$ ): 2008 vw, 1942 w, 1903 w, 1836 s, 1822 s (mer) 2009 vw, 1909 s, 1821 s (fac). - MS (FAB): m/z [M] $]^{+} 730,[\mathrm{M}]^{+}$- (CO) 702, [M] - 2(CO) 674, [M] - 3(CO) 646. - Anal Calc. for $\mathrm{C}_{40} \mathrm{H}_{39} \mathrm{~N}_{1} \mathrm{O}_{3} \mathrm{P}_{2} \mathrm{~S}_{1} \mathrm{Cr}_{1}$ : C, 66.02; H, 5.40. Found: C, 66.43; H, 5.48.

Complex 4: Yield = 72\%; NMR ${ }^{1} \mathrm{H}\left(\mathrm{CD}_{2} \mathrm{Cl}_{2}, \delta(\mathrm{ppm}), \mathrm{J}(\mathrm{Hz})\right): 8.65$ (s, 1H, NH), $7.45(\mathrm{dd}, \mathrm{J}=1.8$, 0.9 Hz, 1H, H8), 7.01 (dd, J = 3.5, 0.8 Hz, 1H, H10), 6.50 (dd, J = 3.5, 1.8 Hz, 1H, H9), 7.25-7.40, 7.44-7.72 (m, 20H, Ph), 3.77 (m, 1H, H11), 2.60-2.69 (m, 2H, PCH17), 2.41-2.53 (m, 2H, PCH18), 1.20-1.60 (m, H12-H14). ${ }^{13} \mathrm{C}$ NMR (CD $\left.2 \mathrm{Cl}_{2}, \mathrm{ppm}\right): 262.6$ (C6), 235.5 (CO), 229.0 (CO), 220.1 (CO), 157.8 (C7), 143.5 (C10), 129.7 (C8), 118.7 (C9), 138.5, 131.8, 131.3, 129.1 (Ph), 59.8 (C11), 30.7 (C12), 25.5 (C14), 24.4 (C13), 33.2 (PC17), 31.5 (PC18). ${ }^{31} \mathrm{P}$ ((CD $\left.)_{2} \mathrm{CO}, \mathrm{ppm}\right): 80.8,77.9$ (mer), 78.0 (fac). IR (cm-1): 2008 vw, 1943 w, 1915 w, 1844 s, 1827 s (mer) 2008 vw, 1915 s, 1830

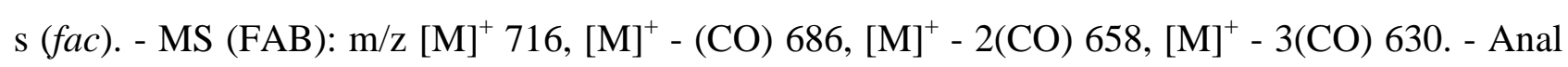
Calc. for $\mathrm{C}_{40} \mathrm{H}_{39} \mathrm{~N}_{1} \mathrm{O}_{4} \mathrm{P}_{2} \mathrm{Cr}_{1}$ : C, 67.51; H, 5.52. Found: C, 67.78; H, 5.82.

[Cr(CO) $)_{5} \mathrm{C}(\mathrm{OEt})\left(2-\right.$ thienyl)] [28] (5) and [Cr(CO) $\left.{ }_{5} \mathrm{C}(\mathrm{OEt})(2-f u r y l)\right] ~[28,29]$ (6) were prepared according to known literature procedures and the spectroscopic characterization data supplied.

Complex 5: Yield = 82\%; NMR $\left(\mathrm{CDCl}_{3}\right){ }^{1} \mathrm{H}(\delta(\mathrm{ppm}), \mathrm{J}(\mathrm{Hz})): 8.24(\mathrm{~d}, \mathrm{~J}=4.2 \mathrm{~Hz}, 1 \mathrm{H}, \mathrm{H} 8), 7.67(\mathrm{~d}$, $\mathrm{J}=4.6 \mathrm{~Hz}, 1 \mathrm{H}, \mathrm{H} 10), 7.20$ (dd, J = 4.9, 4.2 Hz, 1H, H9), 5.16 (q, J = 7.0 Hz, 2H, CH $)^{2}, 1.65$ (t, J = $\left.7.0 \mathrm{~Hz}, 3 \mathrm{H}, \mathrm{CH}_{3}\right) .{ }^{13} \mathrm{C} \mathrm{NMR}\left(\mathrm{CDCl}_{3}, \mathrm{ppm}\right): 316.5$ (C6), 223.6 (CO trans), 217.1 (CO cis), 155.4 (C7), 141.0 (C8), 134.8 (C10), 129.0 (C9), $77.1\left(\mathrm{CH}_{2}\right), 15.4\left(\mathrm{CH}_{3}\right)$. IR (KBr, $\left.\mathrm{cm}^{-1}\right)$ : $\left.2059 \mathrm{~m}\left(\mathrm{~A}_{1}\right)\right)$, 1987 vw (B), 1955 s (A'1), 1947 vs (E).

Complex 6: Yield = 74\%; NMR $\left(\mathrm{CDCl}_{3}\right){ }^{1} \mathrm{H}(\delta(\mathrm{ppm}), \mathrm{J}(\mathrm{Hz})): 7.82(\mathrm{~d}, \mathrm{~J}=3.7 \mathrm{~Hz}, 1 \mathrm{H}, \mathrm{H} 10), 6.96$ (d, J = 3.7 Hz, 1H, H8), 6.56 (dd, J = 3.7, 3.6 Hz, 1H, H9), 5.15 (q, J = 6.9 Hz, 2H, CH2), 1.67 (t, J $\left.=7.0 \mathrm{~Hz}, 3 \mathrm{H}, \mathrm{CH}_{3}\right) \cdot{ }^{13} \mathrm{C} \mathrm{NMR}\left(\mathrm{CDCl}_{3}, \mathrm{ppm}\right): 310.8$ (C6), 223.9 (CO trans), 216.8 (CO cis), 164.1 (C7), 149.9 (C8), 112.9 (C10), 111.8 (C9), $75.8\left(\mathrm{CH}_{2}\right), 15.3\left(\mathrm{CH}_{3}\right)$. - IR (KBr, cm $\left.{ }^{-1}\right)$ : $2060 \mathrm{~m}\left(\mathrm{~A}_{1}\right)^{\prime}$, $1985 \mathrm{vw}(\mathrm{B}), 1922$ vs (A' 1 and E, overlap).

\section{Crystallography}

Crystals suitable for single crystal X-ray crystallography were obtained for the mer isomers of 1-4 and the fac isomers of $\mathbf{1}$ and $\mathbf{4}$. The experimental data are presented in Table 1 and Table 2. Data for fac-1, fac-4 and mer-4, were collected at $150 \mathrm{~K}$ on a Bruker D8 Venture kappa geometry diffractometer, with duo I $\mu$ s sources, a Photon 100 CMOS detector and APEX II [14] control 
software using Quazar multi-layer optics monochromated, Mo-Ka radiation by means of a combination of $\phi$ and $\omega$ scans. Data for mer-1 were collected at 100(2) K, using a Bruker APEX DUO 4K-CCD diffractometer. Data reduction was performed using SAINT+ [14] and the intensities were corrected for absorption using SADABS [14]. The structures were solved by intrinsic phasing using SHELXTS [15] and refined by full-matrix least squares using SHELXTL and SHELXL97/2013 [15]. In the structure refinement all hydrogen atoms were added in calculated positions and treated as riding on the atom to which they are attached. All non-hydrogen atoms were refined with anisotropic displacement parameters, all isotropic displacement parameters for hydrogen atoms were calculated as $\mathrm{X} \times$ Ueq of the atom to which they are attached, $\mathrm{X}=1.5$ for the methyl hydrogens and 1.2 for all other hydrogens.

Data for mer-2 and mer-3 were collected at 180(2) K on a Nonius Kappa CCD diffractometer, using graphite monochromated, Mo K $\alpha$ radiation by means of phi and omega scans. Structures were solved by direct methods using SHELXS-97 [15] and refined by full-matrix least square techniques using SHELXL-2013 [15]. In the structure refinements all hydrogen atoms were added in calculated positions and treated as riding on the atom to which they are attached. Nonhydrogen atoms were refined with anisotropic displacement parameters, all isotropic displacement parameters for hydrogen atoms were calculated as $X \times U_{e q}$ of the atom to which they are attached, $X=1.5$ for the methyl hydrogens and 1.2 for all other hydrogens. Semi-empirical absorption corrections were based on equivalence and the refinement methods used were full-matrix leastsquares based on $\mathrm{F}^{2}$.Ortep drawings [16] of the six structures are included in figures 2-7 with ADP's at the 50\% probability level. The crystal structures have been deposited at the Cambridge Crystallographic Data Centre and allocated the deposition numbers: CCDC 946104, CCDC 946098, CCDC 946103, CCDC 946261, CCDC 946262, CCDC 946260.

Table 1: Crystal data and structure refinement for mer-1, mer-2 and mer-3

\begin{tabular}{|c|c|c|c|}
\hline Identification code & mer-1 & mer-2 & mer-3 \\
\hline Empirical formula & $\mathrm{C}_{36} \mathrm{H}_{32} \mathrm{CrO}_{4} \mathrm{P}_{2} \mathrm{~S}$ & $\mathrm{C}_{36} \mathrm{H}_{32} \mathrm{CrO}_{5} \mathrm{P}_{2}$ & $\mathrm{C}_{40} \mathrm{H}_{39} \mathrm{CrNO}_{3} \mathrm{P}_{2} \mathrm{~S}$ \\
\hline Formula weight & 674.61 & 658.56 & 812.65 \\
\hline Temperature & $180(2) \mathrm{K}$ & $180(2) \mathrm{K}$ & $100(2) \mathrm{K}$ \\
\hline Crystal system & Monoclinic & Orthorhombic & Monoclinic \\
\hline Space group & $P 2_{1} / n$ & P b c n & $\mathrm{P} 21 / \mathrm{m}$ \\
\hline \multirow[t]{6}{*}{ Unit cell dimensions } & $\mathrm{a}=15.1358(4)) \AA$ & $\mathrm{a}=286325(6) \AA$ & $\mathrm{a}=15.5785(10) \AA$ \\
\hline & $\mathrm{b}=11.7118(4) \AA$ & $\mathrm{b}=11.2991(2) \AA$ & $\mathrm{b}=11.6413(7) \AA$ \\
\hline & $c=17.4351(5) \AA$ & $c=24.0498(5) \AA$ & $\mathrm{c}=17.2518(11) \AA$ \\
\hline & $\alpha=90^{\circ}$ & $\alpha=90^{\circ}$ & $\alpha=90^{\circ}$ \\
\hline & $\beta=97.573(2)^{\circ}$ & $\beta=90^{\circ}$ & $\beta=96.252(2)^{\circ}$ \\
\hline & $\gamma=90^{\circ}$ & $\gamma=90^{\circ}$ & $\gamma=90^{\circ}$ \\
\hline
\end{tabular}




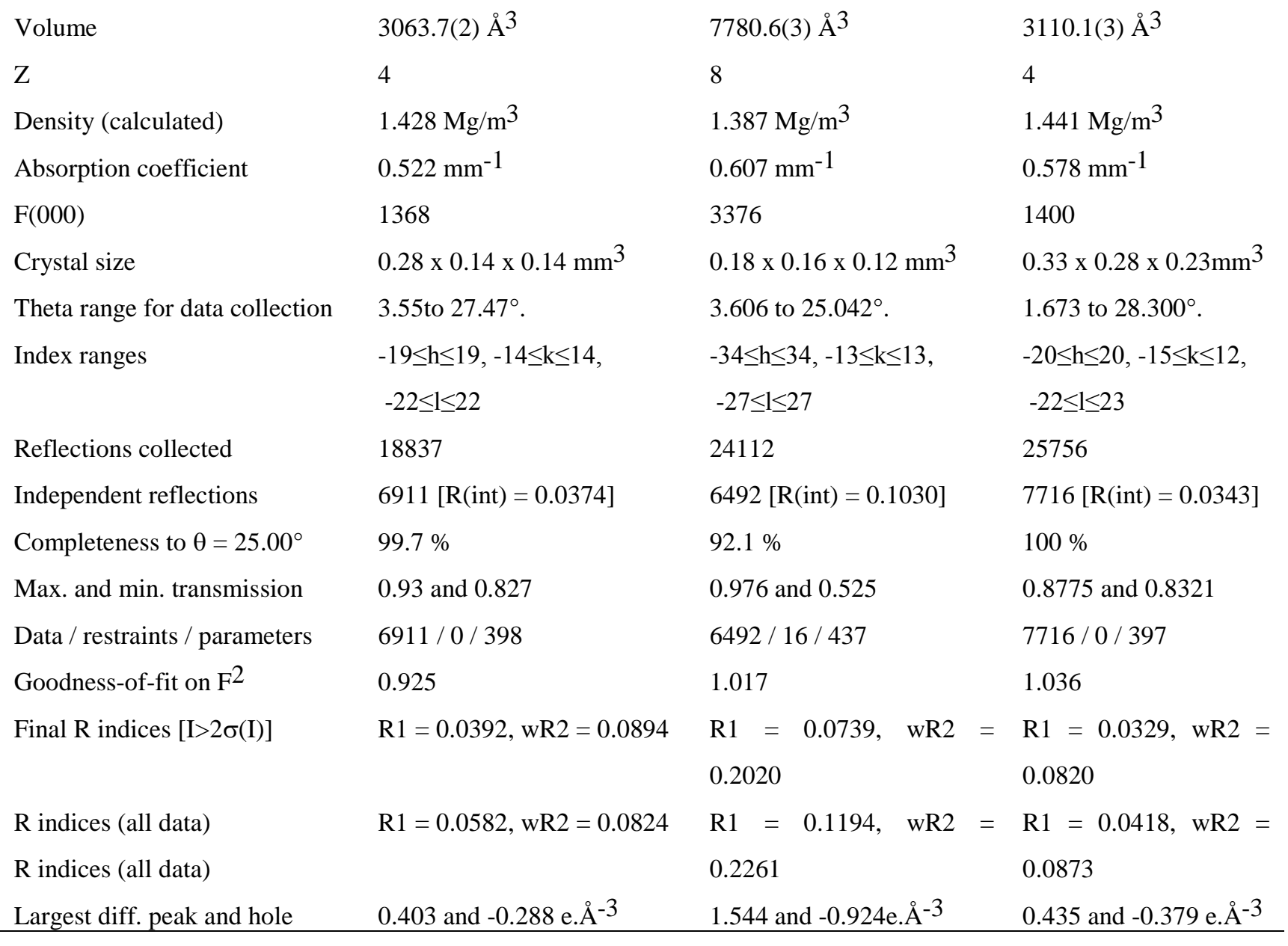

Table 2 Crystal data and structure refinement for fac-1, fac-4 and mer-4

\begin{tabular}{llll}
\hline Identification code & $f a c-1$ & $f a c-4$ & $m e r-4$ \\
Empirical formula & $\mathrm{C}_{36} \mathrm{H}_{32} \mathrm{CrO}_{4} \mathrm{P}_{2} \mathrm{~S}$ & $\mathrm{C}_{40} \mathrm{H}_{39} \mathrm{CrNO}_{4} \mathrm{P}_{2}$ & $\mathrm{C}_{40} \mathrm{H}_{39} \mathrm{CrNO}_{4} \mathrm{P}_{2}$ \\
Formula weight & 674.62 & 710.65 & 785.78 \\
Temperature & $150(2) \mathrm{K}$ & $150(2) \mathrm{K}$ & $150(2) \mathrm{K}$ \\
Crystal system & Monoclinic & Monoclinic & Monoclinic \\
Space group & $\mathrm{P} 2{ }_{1} / \mathrm{c}$ & $\mathrm{P} 2{ }_{1} / \mathrm{n}$ & $\mathrm{P} 2{ }_{1} / \mathrm{n}$ \\
Unit cell dimensions & $\mathrm{a}=11.6587(16) \AA$ & $\mathrm{a}=10.9508(3) \AA$ & $\mathrm{a}=18.9405(7) \AA$ \\
& $\mathrm{b}=18.321(3) \AA$ & $\mathrm{b}=16.9938(5) \AA$ & $\mathrm{b}=11.4003(5) \AA$ \\
& $\mathrm{c}=15.064(2) \AA$ & $\mathrm{c}=18.5697(5) \AA$ & $\mathrm{c}=19.9155(7) \AA$ \\
& $\alpha=90^{\circ}$ & $\alpha=90^{\circ}$ & $\alpha=90^{\circ}$ \\
Volume & $\beta=95.313(4)^{\circ}$ & $\beta=91.331(1) \circ$ & $\beta=113.163(1)^{\circ}$ \\
Z & $\gamma=90^{\circ}$ & $\gamma=90^{\circ}$ & $\gamma=90^{\circ}$ \\
Density (calculated) & $3203.8(8)) \AA^{3}$ & $3454.81(6) \AA^{3}$ & $3953.7(3) \AA^{3}$
\end{tabular}




\begin{tabular}{|c|c|c|c|}
\hline $\mathrm{F}(000)$ & 1400 & 1484 & 1656 \\
\hline Crystal size & $0.39 \times 0.08 \times 0.08 \mathrm{~mm}^{3}$ & $0.29 \times 0.13 \times 0.08 \mathrm{~mm}^{3}$ & $0.23 \times 0.17 \times 0.14 \mathrm{~mm}^{3}$ \\
\hline Theta range for data collection & 2.223 to $29.669^{\circ}$. & 2.181 to $33.03^{\circ}$. & 2.185 to $28.770^{\circ}$. \\
\hline Index ranges & $\begin{array}{l}-16 \leq h \leq 16,-25 \leq k \leq 25, \\
-20 \leq 1 \leq 20\end{array}$ & $\begin{array}{l}-16 \leq \mathrm{h} \leq 16,-26 \leq \mathrm{k} \leq 26, \\
-28 \leq 1 \leq 28\end{array}$ & $\begin{array}{l}-25 \leq \mathrm{h} \leq 25,-15 \leq \mathrm{k} \leq 15, \\
-26 \leq 1 \leq 26\end{array}$ \\
\hline Reflections collected & 107017 & 167115 & 123154 \\
\hline Independent reflections & $9022[\mathrm{R}(\mathrm{int})=0.0595]$ & $13225[\mathrm{R}(\mathrm{int})=0.0447]$ & $10261[\mathrm{R}(\mathrm{int})=0.0674]$ \\
\hline Completeness to $\theta=25.00^{\circ}$ & $99.9 \%$ & $100.0 \%$ & $99.9 \%$ \\
\hline Max. and min. transmission & 0.7459 and 0.6435 & 0.7465 and 0.6979 & 0.7457 and 0.6838 \\
\hline Data / restraints / parameters & 9022 / 0 / 397 & 13225 / 0 / 433 & 10261 / 0 / 482 \\
\hline Goodness-of-fit on $\mathrm{F}^{2}$ & 1.049 & 1.057 & 1.029 \\
\hline Final $R$ indices $[\mathrm{I}>2 \sigma(\mathrm{I})]$ & $\mathrm{R} 1=0.0364, \mathrm{wR} 2=0.0905$ & $\begin{array}{l}\mathrm{R} 1=0.0351, \quad \mathrm{wR} 2= \\
0.0909\end{array}$ & $\begin{array}{l}\mathrm{R} 1=0.0412, \quad \mathrm{wR} 2 \\
0.0862\end{array}$ \\
\hline $\mathrm{R}$ indices (all data) & $\mathrm{R} 1=0.0508, \mathrm{wR} 2=0.0994$ & $\begin{array}{l}\mathrm{R} 1=0.0474, \quad \mathrm{wR} 2= \\
0.0978\end{array}$ & $\begin{array}{l}\mathrm{R} 1=0.0724, \quad \mathrm{wR} 2 \\
0.0976\end{array}$ \\
\hline Largest diff. peak and hole & 0.868 and -0.787 e. $\AA^{-3}$ & 1.007 and -0.240 e. $\AA^{-3}$ & 0.432 and -0.384 e. $\AA^{-3}$ \\
\hline
\end{tabular}

\section{Cyclic Voltammetry}

Cyclic voltammograms (CV's) and linear sweep voltammograms (LSV's) measurements were performed on $0.0005 \mathrm{~mol} \mathrm{dm}{ }^{-3}$ compound solutions in dry acetonitrile. Tetra- $n$-butylammonium hexafluorophosphate, $\left(\left[\mathrm{N}\left({ }^{\mathrm{n}} \mathrm{Bu}_{4}\right)\right]\left[\mathrm{PF}_{6}\right]\right),\left(0.1 \mathrm{~mol} \mathrm{dm}^{-3}\right)$ was used as supporting electrolyte. The CV's were collected under a blanket of purified argon at $25^{\circ} \mathrm{C}$ utilizing a Princeton Applied Research PARSTAT 2273 voltammograph running PowerSuite (Version 2.58). A three-electrode cell, with a glassy carbon (surface area $7.07 \times 10^{-6} \mathrm{~m}^{2}$ ) working electrode, Pt auxiliary electrode and a $\mathrm{Ag} / \mathrm{Ag}^{+}$(0.010 mol dm${ }^{-3} \mathrm{AgNO}_{3}$ in $\left.\mathrm{CH}_{3} \mathrm{CN}\right)$ reference electrode [17] mounted on a Luggin capillary, was used $[18,19]$. All temperatures were kept constant to within $0.5{ }^{\circ} \mathrm{C}$. Scan rates were $0.050-5.000 \mathrm{~V} \mathrm{~s}^{-1}$. Successive experiments under the same experimental conditions showed that all oxidation and formal reduction potentials were reproducible within $6 \mathrm{mV}$. All cited potentials were referenced against the $\mathrm{FcH} / \mathrm{FcH}^{+}$couple as suggested by IUPAC [20]. Ferrocene exhibited a formal reduction potential $E^{\circ \prime}=0.079 \mathrm{~V} v$ s. $\mathrm{Ag} / \mathrm{Ag}^{+}$, a peak separation $\Delta E_{\mathrm{p}}=E_{\mathrm{pa}}-E_{\mathrm{pc}}=0.069 \mathrm{~V}$ and $i_{p c} / i_{p a}=0.98$ under our experimental conditions. $E_{\mathrm{pa}}\left(E_{\mathrm{pc}}\right)=$ anodic (cathodic) peak potential and $i_{p a}\left(i_{p c}\right)=$ anodic (cathodic) peak current. $E^{\circ}\left(\mathrm{FcH} / \mathrm{FcH}^{+}\right)=0.66(5) \mathrm{V}$ vs. SHE in $\left[\mathrm{NBu}_{4}\right] / \mathrm{CH}_{3} \mathrm{CN}$ and $0.77(5) \mathrm{V}$ vs. SHE in $\left[\mathrm{NBu}_{4}\right] / \mathrm{DCM}[21]$. 


\section{DFT calculations}

All density functional theory (DFT) calculations were carried out using the hybrid functional B3LYP [22,23] as implemented in the Gaussian 09 program package [24]. Geometries were optimized in gas phase with the triple- $\zeta$ basis set 6-311G(d,p) on all atoms except chromium, where LANL2DZ was used (corresponding to the Los Alamos Effective Core Potential plus DZ [25]). Calculations taking solvation effects into account did not alter the character of the frontier orbitals or the relationship relative to experimental values [26].

\section{Results and discussion}

\section{Synthesis}

Classic Fischer methodology [3] was employed to synthesise the Cr carbene starting complexes [(CO) $)_{5} \mathrm{Cr}=\mathrm{C}(\mathrm{X}) \mathrm{R}$ ] [27-29] with $\mathrm{R}=$ 2-thienyl (5) or 2-furyl (6) (Scheme 1). The first reaction stage in the multi-step synthesis requires a strong base to deprotonate the $\alpha$-proton on the heteroarene. The base $\mathrm{n}-\mathrm{BuLi}$ was used to deprotonate the heteroarene ring at $-78{ }^{\circ} \mathrm{C}$, under inert conditions and with dry THF as solvent. Chromium hexacarbonyl was added in a single portion at $78{ }^{\circ} \mathrm{C}$ and the reaction followed a nucleophilic mechanism in which an electrophilic metal carbonyl carbon is attacked by the newly formed nucleophilic, deprotonated heteroarene ring. The chromium metal acylate is formed as product. The solvent was removed under vacuum and the resulting residue dissolved in dichloromethane. Subsequent alkylation of the acylate with triethyl oxonium salt at $-30{ }^{\circ} \mathrm{C}$ yielded the desired monocarbene complex 5 or $\mathbf{6}$. The synthetic procedure for the carbene starting complexes 5 and $\mathbf{6}$ has been reported in literature previously [28,29]. The complexes were purified using column chromatography with hexane and dichloromethane (DCM) as eluents. Yields of between $74 \%$ and $82 \%$ were obtained. 


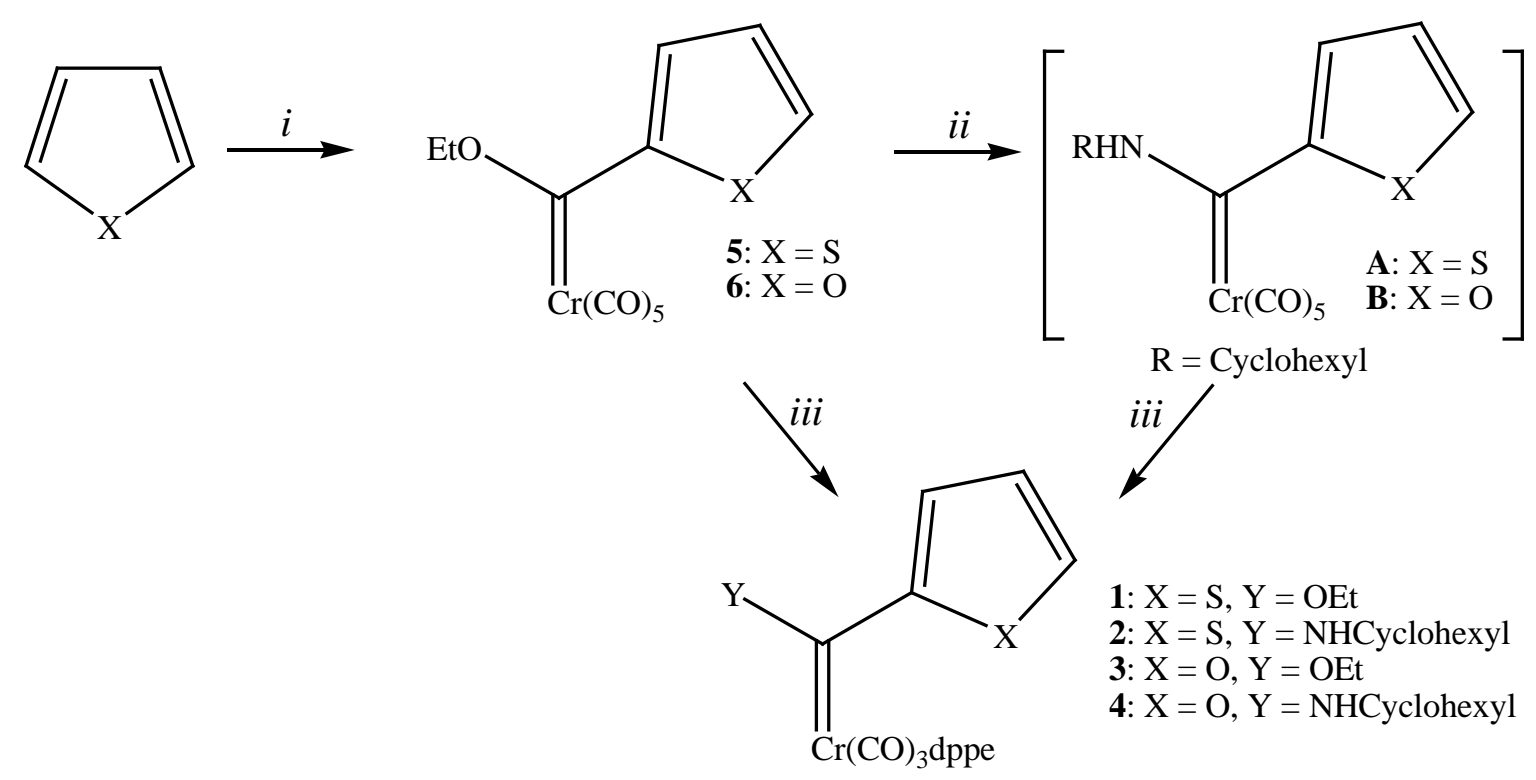

Scheme 1 Synthesis of the chromium(0) carbene complexes.

Reagents and conditions: (i) a. 1.1 eq. n-BuLi, THF, $-20^{\circ} \mathrm{C}$; b. 1 eq. $\mathrm{Cr}(\mathrm{CO})_{6}$, thf, $-40^{\circ} \mathrm{C}$; c. $\mathrm{Et}_{3} \mathrm{OBF}_{4}, \mathrm{CH}_{2} \mathrm{Cl}_{2},-20^{\circ} \mathrm{C}$. (ii) 1 eq. cyclohexylamine, rt; (iii) 1 eq. dppe, toluene, $90^{\circ} \mathrm{C}$.

Modification of Fischer carbene complexes via nucleophilic substitution of the alkoxy carbene substituent is well known in the literature [30]. In the reaction of the Fischer carbene with a primary amine, cyclohexylamine, an immediate colour change was observed from bright red for the alkoxy carbene complexes (5 or 6) to a yellow-orange coloured aminocarbene complex (A or B), (Scheme 1).

Substitution of two carbonyl ligands with a bidentate dppe ligand was accomplished by refluxing the carbene starting material, 5 or $\mathbf{6}$, in toluene [7,31] to produce substituted Fischer carbene complexes $\mathbf{1}, \mathbf{2}, \mathbf{3}$, and $\mathbf{4}$. The reaction mixture was refluxed at $90{ }^{\circ} \mathrm{C}$ until tlc (thin layer chromatography) analysis indicated completeness of the reaction. Bidentate ligated monocarbene complexes 1-4 were obtained with yields of $63-72 \%$. Literature reports suggest that both isomers can be obtained, but that the type of isomer formed depends on the metal. The fac isomer seems to be favoured for molybdenum complexes [7], especially at high reaction temperatures. This isomer was predominantly observed by Reinheimer et al. [31] for complexes fac[(dppe)(CO) $\left.{ }_{3} \mathrm{M}=\mathrm{C}(\mathrm{OR}) \mathrm{R}^{\prime}\right], \mathrm{R}^{\prime}=\mathrm{Me}, \mathrm{Ph} ; \mathrm{M}=\mathrm{Cr}, \mathrm{W}$ as well as by Arrieta et al. [32] in the formation of fac-[(dppe)(CO) $\left.)_{3} \mathrm{Cr}=\mathrm{C}(\mathrm{OEt}) \mathrm{Me}\right]$ by thermal substitution of the corresponding pentacarbonyl complex with dppe. Barluenga et. al. [7] observed isomerization of the kinetic facproduct to the mer-isomer upon prolonged heating at $100{ }^{\circ} \mathrm{C}$ in toluene.

Both isomers were isolated from our reactions (Figure 1) and the X-ray crystal data of all four of the mer and two of the fac isomers of 1-4 obtained. Both isomers crystallized from the same solution and the crystals were separated manually. To our knowledge, this is the first report on the 
isolation and structural identification of both fac- and mer isomers from the same carbene solution mixture. In all cases the mer isomers were darker coloured (black) than the fac isomers (redorange). Upon dissolving either the pure fac or pure mer isomer, equilibrium between the two isomers sets in. On the ${ }^{1} \mathrm{H}$ and ${ }^{13} \mathrm{C}$ NMR spectra of the solution containing both isomers, only one set of peaks was observed, implying that the isomers could not be distinguished from one another on the ${ }^{1} \mathrm{H}$ and ${ }^{13} \mathrm{C}$ spectra. However, two sets of peaks were observed on the ${ }^{31} \mathrm{P}$ NMR spectra of the complexes: one set belonging to the mer isomer and one to the fac isomer. This assignment could be confirmed with qualitative ${ }^{31} \mathrm{P}$ NMR spectra recorded at regular intervals over the course of one week. During this time, the relative intensities of the two sets of peaks changed for the various complexes.
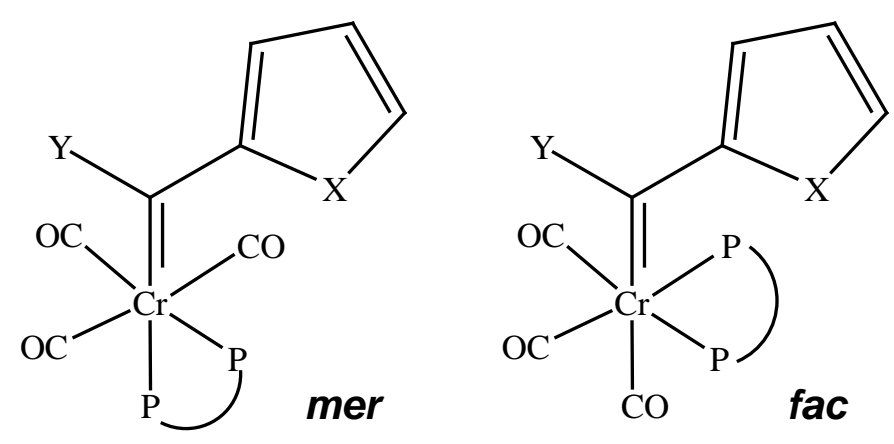

1: $\mathrm{X}=\mathrm{S}, \mathrm{Y}=\mathrm{OEt}$

2: $\mathrm{X}=\mathrm{O}, \mathrm{Y}=\mathrm{OEt}$

3: $\mathrm{X}=\mathrm{S}, \mathrm{Y}=$ NHCyclohexyl

4: $\mathrm{X}=\mathrm{O}, \mathrm{Y}=\mathrm{NHCyclohexyl}$

Figure 1 Fac and mer isomers of the novel carbene complexes 1-4

\section{Characterisation}

Since the products were only marginally soluble in $\mathrm{CDCl}_{3}$, different deuterated solvents were used to obtain the best possible spectrum. The novel complexes 1-4 were fully characterised using either $\mathrm{CD}_{2} \mathrm{Cl}_{2}, \mathrm{CD}_{3} \mathrm{CN}$ or $\left(\mathrm{CD}_{3}\right)_{2} \mathrm{CO}$ as deuterated solvents for NMR spectroscopy and $\mathrm{KBr}$ pellets for infrared spectroscopy. Solid state infrared characterisation limited the solvent effect and thus the problem of solubility could be circumvented.

The difference in electronic environment of a heteroarene ring substituent in a metal carbene complex has a marked effect on the positions of the resonances in the NMR spectra compared to the free heteroarene rings [33,34]. The electron-withdrawing nature of the metal moiety is evident in the downfield shift of all the heteroarene ring protons. Thiophene monocarbene complexes, 
compared to the furan analogues, display a greater downfield shift for the proton in closest proximity to the carbene ligand. The resonance peak of this proton, H8, is observed most downfield, followed by that of $\mathrm{H} 10$ and then the doublet of doublets associated with H9 [35], see Figures 2-7 for the atom numbering of the complexes. For the furan monocarbene complexes this order is different, with the doublet assigned to H10 found more downfield than that of H8 [29]. This sequence is repeated on the spectra of the substituted carbene complexes 1-4. Although many of the spectra were recorded in different solvents, the trend persists that all resonance peaks observed for the heteroarene ring protons of the dppe carbene derivatives (1-4) were shifted more upfield than the corresponding resonance peaks of the two pentacarbonyl carbene complexes (5 and $\mathbf{6})$. This corresponds to the data found for monophosphine carbene complexes [2], which implies less ring involvement in stabilizing the electrophilic carbene carbon. By substituting stronger $\pi$-acceptor ligands (CO) with weaker ones (dppe) allows for increased electron density contribution from the metal to the carbene carbon. The protons on the phenyl rings of the dppe ligand for 1-4 displayed two multiplets with the more downfield of the two integrating for four protons. This resonance was thus assigned to the para-hydrogens of the four phenyl rings. The proton data is supported by ${ }^{13} \mathrm{C}$ NMR data of the complexes. Carbene carbon and carbonyl carbon resonances are in good agreement with data reported for other phosphine-substituted tricarbonyl carbene complexes. ${ }^{7,31,32}$ The carbonyl ligand peaks of 1-4 are shifted more downfield compared to the corresponding pentacarbonyl complexes. This can be seen as an additive effect of multiple carbonyl substitutions. Also, downfield shifts of carbonyls are indicative of increased metal $\pi$-bonding [36], as would be expected for a greater degree of carbonyl substitution. The carbene carbon resonances of the aminocarbene complexes 3 and $\mathbf{4}$ show the characteristic upfield shift [37-39 of 40-60 ppm compared to the ethoxycarbene analogues. This is ascribed to better $\pi$-donor ability of the nitrogen lone pairs of the amino substituent to stabilise the carbene carbon compared to the ethoxy substituent [40]. ${ }^{31} \mathrm{P}$ NMR spectroscopy could be employed to unambiguously discriminate between the two isomers of the novel complexes 1-4 and was used as probe to study the behaviour of the isomers in solution. Two peaks are expected on the ${ }^{31} \mathrm{P}$ NMR spectrum for the mer isomer since the two phosphorous atoms are in non-equivalent positions. For the fac isomer, only one peak is expected. On comparing chemical shift values for the cis and trans isomers of monophosphine substituted carbene complexes [41], the two peaks of the mer isomer could be assigned. The coupling constants observed for $\mathbf{1}$ and $\mathbf{2}$ for the ${ }^{2} \mathrm{~J}_{\mathrm{PP}}$ couplings were smaller in general compared to literature reports [42], but comparable. It is observed that the phosphorous resonance is shifted more upfield when the phosphorous atom is found trans to a carbene ligand (P1) compared to the resonance when the phosphorous atom is found trans to a carbonyl ligand (P2) (atom numbering refer to Figures 3-5 and 7). This can be explained by the $\sigma$-donor, $\pi$-acceptor properties of the trans ligand: carbene $<$ carbonyl. The carbonyl ligand is a better $\pi$-acceptor ligand and competes for 
electron density from the metal, leaving the phosphorous atom deshielded. On the IR spectra, it was also possible to distinguish between the two isomers. For the fac isomer of metal tricarbonyl complexes, $\left[\mathrm{M}(\mathrm{CO})_{3} \mathrm{~L}_{3}\right]$, two strong bands are expected, while for the mer isomer, three bands of varying intensities $[43,44]$. In some cases more than the expected number of bands was observed for 1-4, possibly due to the dissimilarity of the ligands $\left(\mathrm{L}_{\mathrm{a}} \neq \mathrm{L}_{b}=\mathrm{L}_{c}\right)$. However, since the crystals of these isomers were separated manually, the spectra may also reflect a mixture of both isomers. A molecular ion peak, $[\mathrm{M}]^{+}$, was observed in the mass spectra of each of the four novel complexes. The general fragmentation pattern involved successive fragmentation of the carbonyl ligands.

\section{X-ray crystallography}

Crystals suitable for single crystal X-ray structure analyses were obtained for the mer isomers of 1-4 and the fac isomers of 1 and 4. Figures 2-7 show the crystallographic structures and the numbering system used. The solvent of crystallization has been omitted in the figures of both mer-3 and mer-4. The complexes crystallized from 1:1 hexane:dichloromethane or 1:1 hexane:diethyl ether solutions. Only the major orientation of the thienyl substituent in mer-3 is shown in Figure 5, as this structure has some disorder in the thienyl ring. The ring adopts two orientations and the occupancy of the positions of C8, C9, C10 and S1 was refined to a ratio of 73.7:26.3 for S1:C8, as well as for C9:C10. The dichloromethane is also disordered and two positions were refined for both chlorine atoms, converging in a ratio of 57.0:43.0.

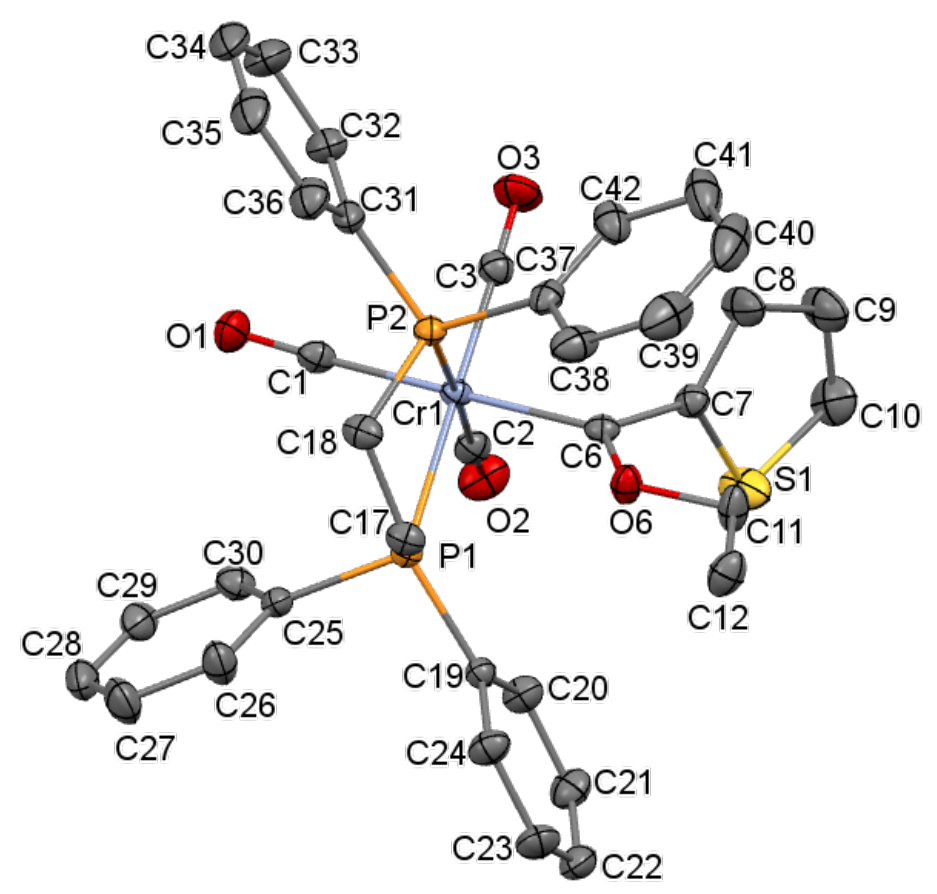


Figure 2 Perspective drawing of the non-hydrogen atoms in fac-1, showing the atom numbering scheme. ADPs are shown at the 50\% probability level.

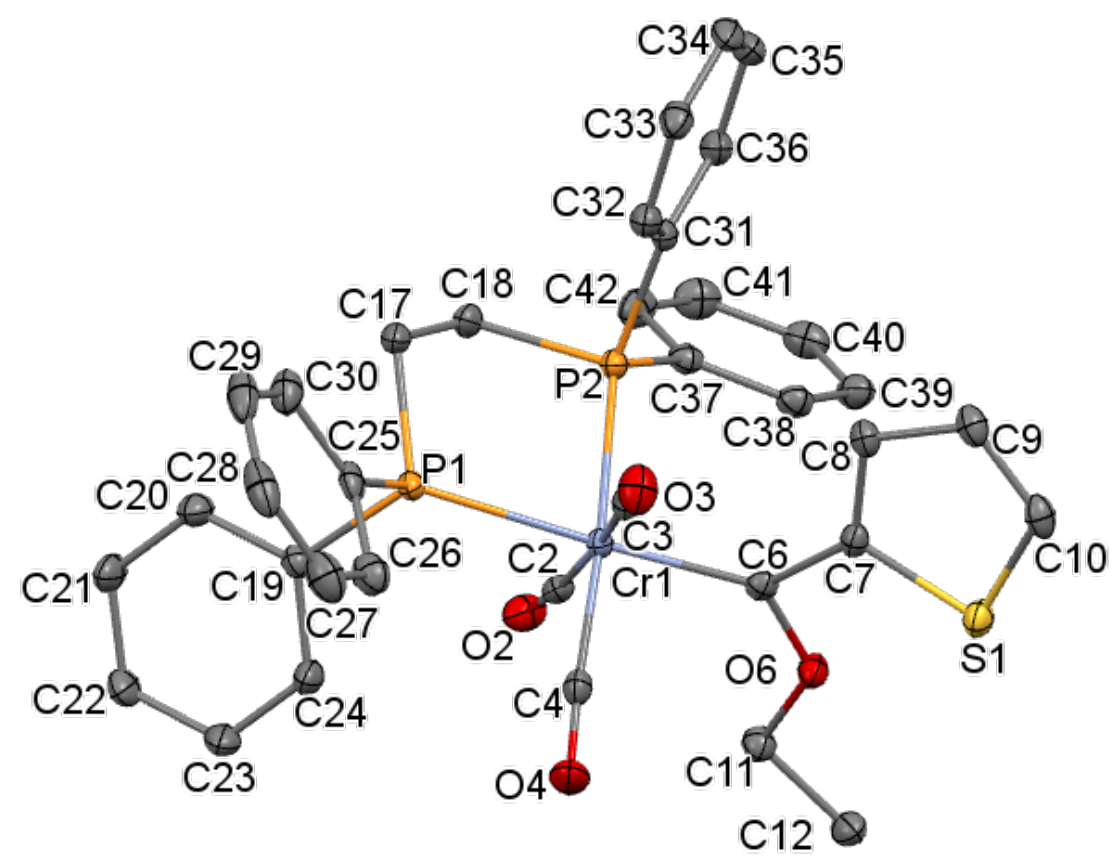

Figure 3 Perspective drawing of the non-hydrogen atoms in mer-1, showing the atom numbering scheme. ADPs are shown at the 50\% probability level.

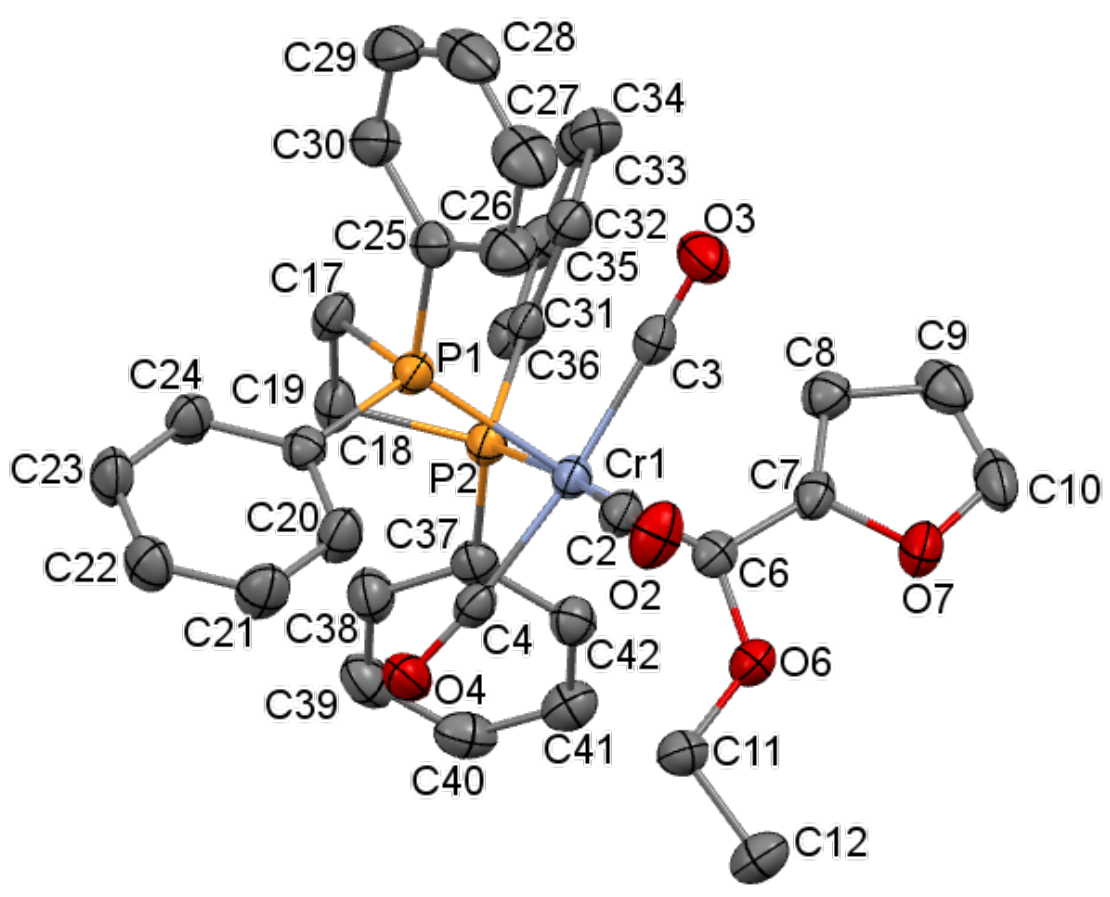

Figure 4 Perspective drawing of the non-hydrogen atoms in mer-2, showing the atom numbering scheme. ADPs are shown at the 50\% probability level. 


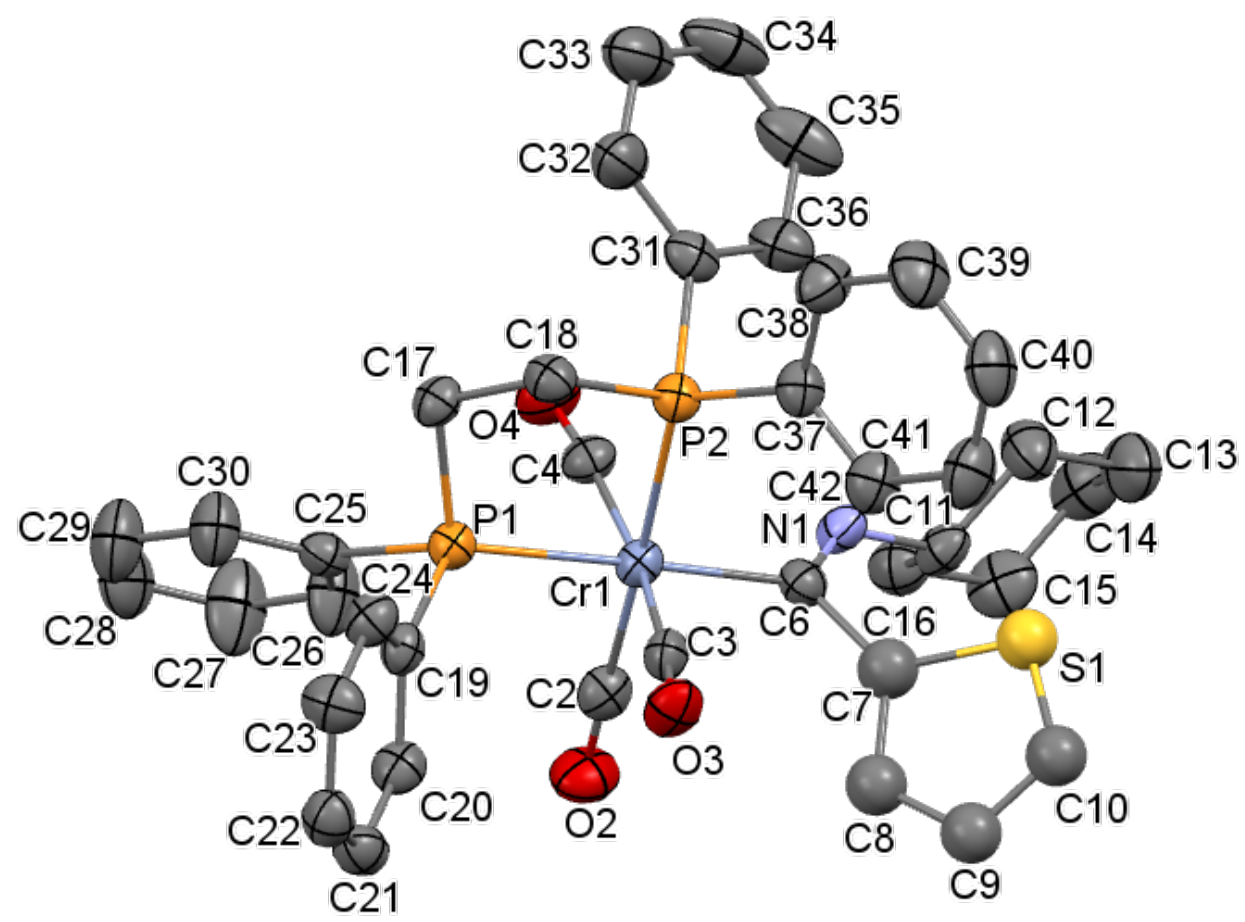

Figure 5 Perspective drawing of the non-hydrogen atoms in mer-3 showing the atom numbering scheme. ADPs are shown at the 50\% probability level.

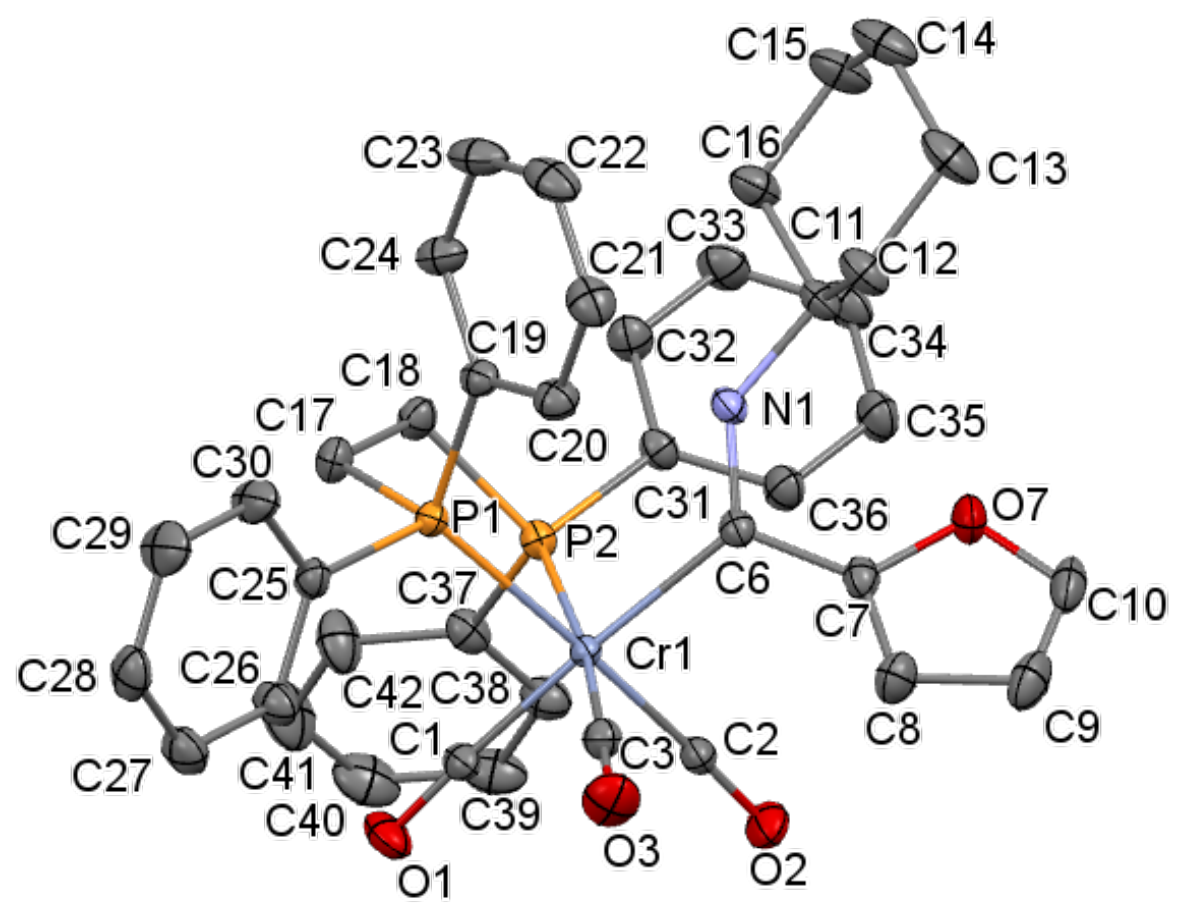

Figure 6 Perspective drawing of the non-hydrogen atoms in fac-4 showing the atom numbering scheme. ADPs are shown at the 50\% probability level. 


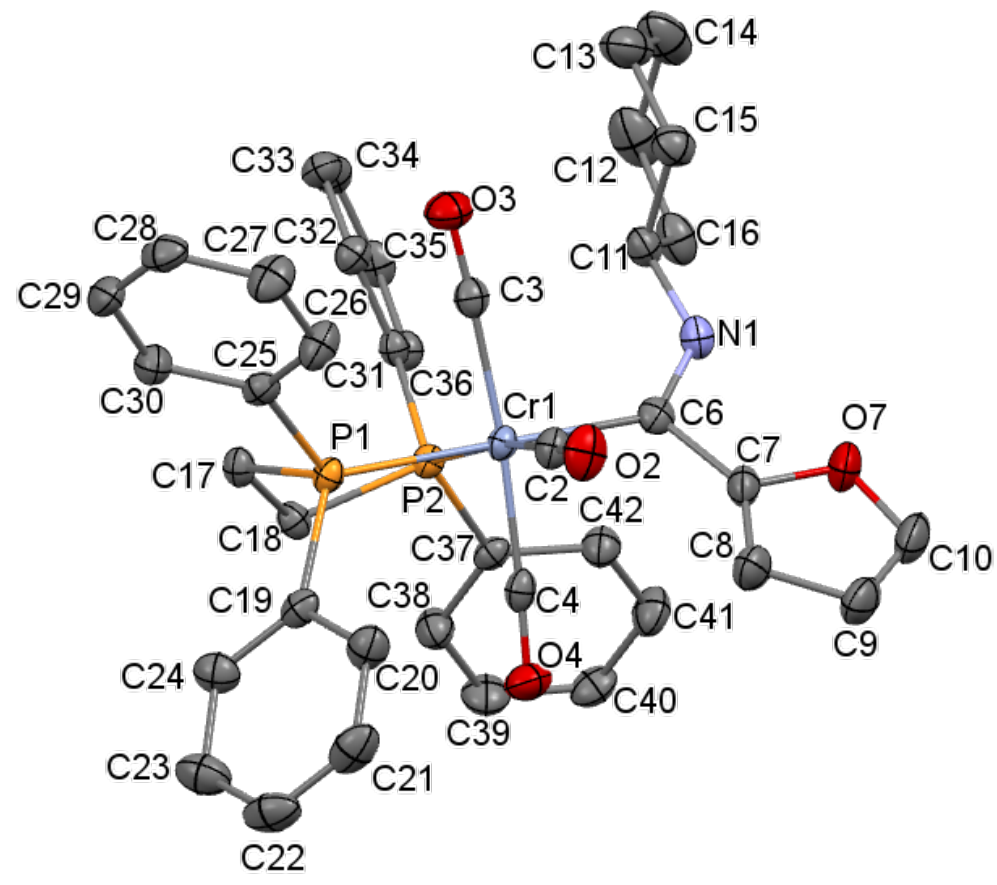

Figure 7 Perspective drawing of the non-hydrogen atoms in mer-4 showing the atom numbering scheme. ADPs are shown at the 50\% probability level.

\section{Structural comparison of the crystallographic structures of 1-4}

Some structural parameters of importance are summarized in Table 3 and Table 4 . Of interest is that in both the fac-complexes the Cr1-C6 carbene bond distances are larger than in the mer-complexes. This bond is also longer for the aminocarbene complexes than for the ethoxy analogues, attesting to the better $\pi$-donor ability of the amino substituent in stabilising the carbene carbon compared to the ethoxy substituent [40]. The distance of 2.084(2) $\AA$ in fac-1 is significantly shorter than the distance of 2.112(2) $\AA$ observed in fac-4. However, the Cr1-C2 bond distances for the carbonyls cis to the carbene bond is $0.058 \AA$ longer in fac-1 than in in fac-4. The Cr1-P bond distances are very similar in all six complexes, although the Cr1-P1 bond in the mer-complexes, trans to the carbene ligand, is consistently shorter than the Cr1-P2 bond, trans to a CO ligand. This trend correlates with the weaker $\pi$-acceptor ability of a carbene ligand compare to a carbonyl ligand. The Cr1-CO bonds lengths of the mer-complexes also reflect this trend. The carbonyl ligand bond lengths trans to carbonyl ligands are all longer than the carbonyl ligand bond length trans to a phosphorus atom. Phosphorus ligands are also weaker $\pi$-acceptor ligands than carbonyls. 
Table 3 Selected geometric parameters for the fac-isomers

\begin{tabular}{|l|l|l|}
\hline Fac complexes & fac-1 & fac-4 \\
\hline Bond length $(\AA)$ & & \\
\hline Cr1-C6 $_{\text {carbene }}$ & $2.084(2)$ & $2.112(1)$ \\
\hline Cr1-C2 $^{\text {a }}$ & $1.902(2)$ & $1.844(1)$ \\
\hline Cr1-C3 $^{\text {a }}$ & $1.850(2)$ & $1.848(1)$ \\
\hline Cr1-C1 $^{\text {b }}$ & $1.884(2)$ & $1.849(1)$ \\
\hline Cr1-P1 & $2.3650(5)$ & $2.3576(3)$ \\
\hline Cr1-P2 $^{\prime}$ & $2.3557(3)$ & $2.3557(3)$ \\
\hline C6-O6/N1 & $1.333(2)$ & $1.323(1)$ \\
\hline C6-C7 & $1.442(2)$ & $1.466(2)$ \\
\hline Bond angle $\left(^{\circ}\right)$ & & \\
\hline P1-Cr1-P2 & $174.7(1)$ & $83.38(1)$ \\
\hline Cr1-C6-O6/N1 & $129.6(1)$ & $122.23(8)$ \\
\hline Cr1-C6-C7 & $124.3(1)$ & $120.77(7)$ \\
\hline O6/N1-C6-C7 & $106.1(2)$ & $116.56(9)$ \\
\hline Torsion angle ( $\left.{ }^{\circ}\right)$ & & \\
\hline O6/N1-C6-C7-S1/O7 & $79.9(2)$ & $-29.7(2)$ \\
\hline Cr1-C6-C7-O7/S1 & $-98.3(1)$ & $142.9(1)$ \\
\hline P1-C17-C18-P2 & $-50.4(1)$ & $46.6(1)$ \\
\hline
\end{tabular}

${ }^{\mathrm{a}} \mathrm{Cr} 1-\mathrm{C}$ bond distance for carbonyls cis to the carbene ligand

${ }^{\mathrm{b}} \mathrm{Cr} 1-\mathrm{C}$ bond distance for carbonyl trans to the carbene ligand

Table 4 Selected geometric parameters for the mer-isomers

\begin{tabular}{|l|l|l|l|l|}
\hline Mer complexes & mer-1 & mer-2 & mer-3 & mer-4 \\
\hline Bond length $(\AA)$ & & & & \\
\hline Cr1-C6 & $1.990(2)$ & $1.994(2)$ & $2.036(5)$ & $2.054(2)$ \\
\hline Cr1-C2 $^{\mathrm{a}}$ & $1.877(2)$ & $1.875(2)$ & $1.885(6)$ & $1.839(2)$ \\
\hline Cr1-C3 $^{\mathrm{a}}$ & $1.884(2)$ & $1.882(2)$ & $1.888(6)$ & $1.882(2)$ \\
\hline Cr1-C4 & & & & \\
\hline Cr1-P1 & $1.852(2)$ & $1.847(2)$ & $1.841(6)$ & $1.872(2)$ \\
\hline Cr1-P2 & $2.369(1)$ & $2.355(1)$ & $2.311(2)$ & $2.324(1)$ \\
\hline C6-O6/N1 & $2.378(1)$ & $2.378(1)$ & $2.356(2)$ & $2.382(1)$ \\
\hline C6-C7 & $1.354(2)$ & $1.352(2)$ & $1.317(7)$ & $1.333(2)$ \\
\hline Bond angle $\left(^{\circ}\right)$ & $1.478(2)$ & $1.467(2)$ & $1.497(8)$ & $1.475(3)$ \\
\hline P1-Cr1-P2 & & & & $83.23(2)$ \\
\hline
\end{tabular}




\begin{tabular}{|l|l|l|l|l|}
\hline Cr1-C6-O6/N1 & $130.77(11)$ & $131.00(13)$ & $124.6(4)$ & $130.68(14)$ \\
\hline Cr1-C6-C7 & $126.23(11)$ & $124.98(12)$ & $121.8(4)$ & $120.57(14)$ \\
\hline O6/N1-C6-C7 & $102.33(13)$ & $103.33(14)$ & $113.5(5)$ & $108.68(16)$ \\
\hline Torsion angle ( $\left.{ }^{\circ}\right)$ & & & & \\
\hline O6/N1-C6-C7-S1/O7 & $-13.2(2)$ & $-14.6(2)$ & $54.6(7)$ & $-7.1(2)$ \\
\hline Cr1-C6-C7-O7/S1 & $158.3(1)$ & $156.7(1)$ & $-129.6(4)$ & $175.6(1)$ \\
\hline P1-C17-C18-P2 & $-54.1(1)$ & $-54.1(1)$ & $52.7(4)$ & $46.6(1)$ \\
\hline
\end{tabular}

${ }^{\mathrm{a}} \mathrm{Cr} 1-\mathrm{C}$ bond distance for carbonyls cis to the carbene ligand

\section{DFT study of the oxidation and reduction of 1-4}

Molecular orbital (MO) calculations by various authors [26,45,46,47,48] on non-phosphine containing Cr-Fischer carbene complexes of the type $\left[(\mathrm{CO})_{5} \mathrm{Cr}=\mathrm{C}(\mathrm{X}) \mathrm{R}\right]$ with $\mathrm{X}=\mathrm{OEt}, \mathrm{NHBu}$, $\mathrm{NMe}_{3}$ or $\mathrm{N}\left(\mathrm{CH}_{2} \mathrm{Ph}\right)_{2}$ and $\mathrm{R}=$ phenyl, thienyl, furyl, NMe-pyrolle, $\mathrm{H}$ or $\mathrm{Me}$, all showed that the highest molecular orbital (HOMO) of these complexes are mainly Cr-metal based, confirming that the first oxidation of these complexes involve $\mathrm{Cr}$, i.e. a $\operatorname{Cr}(0)$ to $\operatorname{Cr}(\mathrm{I})$ oxidation. This assignment is also supported by the spin density plot of the density functional theory (DFT) calculated positively charged paramagnetic species that visualizes the remaining unpaired electron of the oxidized species. This interpretation is related to the Koopmans' theorem [49] stating that the ionisation potential for a neutral gas-phase compound can be approximated by the negative of HOMO energy $\left(E_{\mathrm{HOMO}}\right)$. The energy of the HOMO of the complexes is thus related to the ease of oxidation of the neutral $\mathrm{Cr}$ carbene complex, while the character of the HOMO will show where the oxidation will take place. Following the same line of reasoning, the localization of a second oxidation can be calculated by the HOMO of the oxidized species or a spin density plot of the doubly oxidized species.

To evaluate the influence of phosphine on the oxidation and reduction centre of dppecontaining $\mathrm{Cr}$ carbenes, $\left[(\mathrm{CO})_{3}(\mathrm{dppe}) \mathrm{Cr}=\mathrm{C}(\mathrm{X}) \mathrm{R}\right]$, of this study, a DFT study of the frontier orbitals of both the fac and mer isomers of $\mathbf{1 - 4}$ is presented.

Figure 8 visualize the HOMOs of the neutral fac and mer isomers of $\mathbf{1 - 4}$, as well as the spin density plots of the oxidized fac and mer isomers of 1-4. From Figure 8, it is clear that the oxidation of both the fac and mer isomers of 1-4 of this study is mainly Cr metal-centred. More than $64 \%$ of the HOMO of the fac and mer isomers of $\mathbf{1 - 4}$ is located on Cr, while the spin of the oxidized 1-4, show that the remaining unpaired electron is on $\mathrm{Cr}$ of $\mathrm{d}_{\mathrm{xz}}$ character. 


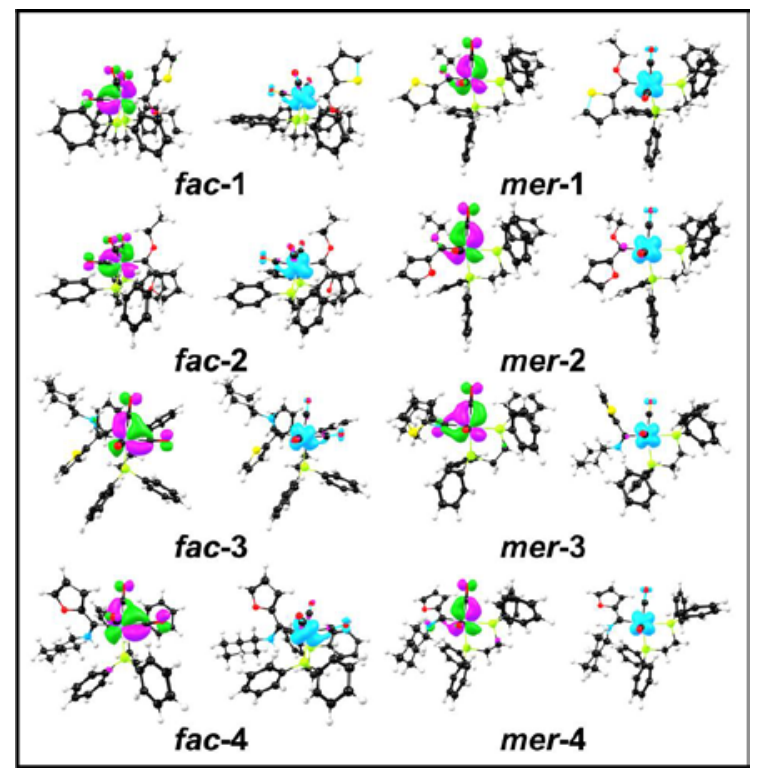

Figure 8 Visualization of the HOMO (magenta and green) of the neutral fac and mer isomers of 14, and the spin density plots (turquois) of the oxidized ( $q=+1, S=1 / 2$ ) fac and mer isomers of 1-4. The MO and spin density plots use a contour of 0.05 and $0.005 \mathrm{e} / \AA^{3}$ respectively. Colour code (online version): Cr light purple, $\mathrm{O}$ red, C black, $\mathrm{P}$ green, $\mathrm{S}$ yellow, $\mathrm{H}$ white.

In evaluating the DFT calculated relative stability of cation of the oxidized fac and mer isomers of 1-4, the mer-cation is found to be at least $0.3 \mathrm{eV}$ more stable than the fac-cation. According to the Boltzmann distribution, this implies that the $\mathrm{fac}^{+} \leftrightarrow \mathrm{mer}^{+}$equilibrium will lead to more than $99.9 \% \mathrm{mer}^{+}$. Therefore, only calculations involving the $\mathrm{mer}^{+}$cation of 1-4 will thus be considered for the second oxidation process.

The second oxidation process involves the removal of a second electron from the neutral species, or the removal of an electron from the HOMO of the oxidized $\mathrm{mer}^{+}$cation (due to the instability of the $\mathrm{fac}^{+}$cation, all $\mathrm{fac}^{+}$will convert to $\mathrm{mer}^{+}$). The first step was to use DFT calculations to determine if the doubly oxidized species is diamagnetic (charge $\mathrm{q}=+2$ and spin $\mathrm{S}=$ 0 , i.e. no unpaired electrons) or paramagnetic (charge $\mathrm{q}=+2$ and spin $\mathrm{S}=1$, i.e. two unpaired electrons). For all the $m e r^{2+}$ species of $\mathbf{1 - 4}$, the paramagnetic $m e r^{2+}$ species with two unpaired electrons was energetically favoured by $0.10-0.65 \mathrm{eV}$. In Figure 9 the HOMOs of the mer $^{+}$cation of 1-4 are visualized. They are mainly of $d_{y z}$ character. Thus, while the first oxidation involved the removal of a $d_{x z}$ electron from the neutral Cr metal centre (Figure 8), the second oxidation involves the removal of a $d_{y z}$ electron from the $\operatorname{Cr}(\mathrm{I})$ metal centre of the mer $^{+}$-cation, see Figure 9 . The spin density plot of the doubly oxidized $\mathrm{mer}^{2+}$ species in Figure 9 is typical of two $\mathrm{d}_{\pi}$ unpaired electrons; one in the $\mathrm{d}_{\mathrm{xz}}$ and one in the $\mathrm{d}_{\mathrm{yz}}$ orbital, resulting in the shape of two doughnuts on top of each other. 


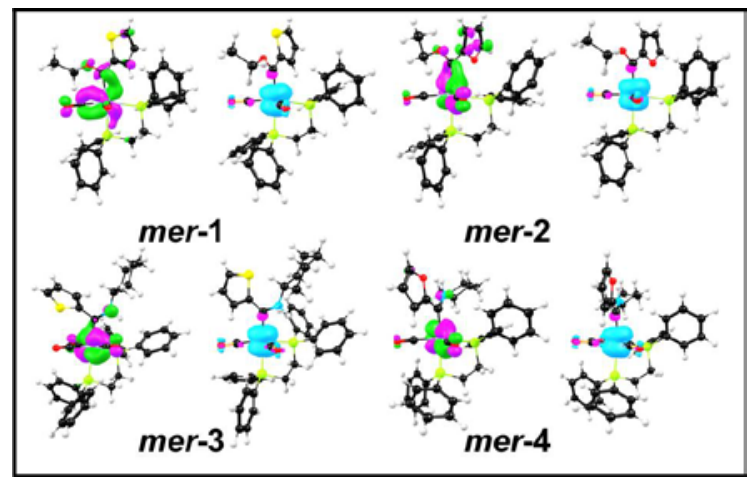

Figure 9 Visualization of the HOMO (magenta and green) of the $\operatorname{mer}^{+}$cation $(\mathrm{q}=+1, \mathrm{~s}=1 / 2)$ and the spin density plots (turquois) of the doubly oxidized $\operatorname{mer}^{2+}$ species $(\mathrm{q}=+2, \mathrm{~S}=1)$ of $\mathbf{1 - 4}$. The MO and spin density plots use a contour of 0.05 and $0.005 \mathrm{e} / \AA^{3}$ respectively. Colour code (online version): Cr light purple, $\mathrm{O}$ red, $\mathrm{C}$ black, $\mathrm{P}$ green, $\mathrm{S}$ yellow, $\mathrm{H}$ white.

From the Koopmans' theorem [49], the energy of the LUMO of the Cr carbene complexes of this study is related to the reduction potential of the neutral complex, while the character of the LUMO shows where the reduction will take place. The localization of the added unpaired electron of the reduced species, can be visualized by a spin-density plot of the reduced species (charge $q=$ 1 , spin $S=1 / 2$ ), see Figure 10. The MO's in Figure 10 show that the centre of reduction of $\mathbf{1 - 4}$ is mainly localized the carbene carbon atom and the heteroarene ring and not on the dppe ligand.

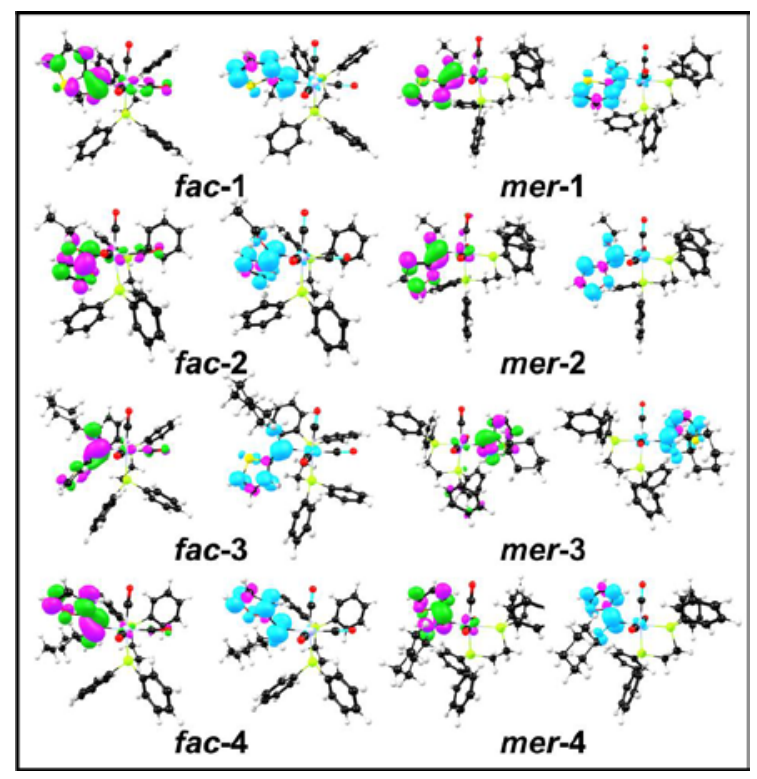

Figure 10 Visualization of the LUMO (magenta and green) of the neutral fac and mer isomers of 14 and the spin density plots (turquois) of the reduced radical anion ( $q=-1, S=1 / 2$ ) of the fac and mer isomers of 1-4. The MO and spin density plots use a contour of 0.05 and 0.005 e/ $/ \AA^{3}$ 
respectively. Colour code (online version): Cr light purple, $\mathrm{O}$ red, $\mathrm{C}$ black, $\mathrm{P}$ green, $\mathrm{S}$ yellow, $\mathrm{H}$ white.

In summary, the DFT calculations indicate that the first and second oxidation processes of the dppe-containing $\mathrm{Cr}$ carbenes, $\left[(\mathrm{CO})_{3}(\mathrm{dppe}) \mathrm{Cr}=\mathrm{C}(\mathrm{X}) \mathrm{R}\right], \mathbf{1 - 4}$ involve the $\mathrm{Cr}$ metal centre, while the first reduction process leads to a radical anion with the electron density distributed on the carbene carbon and the heteroarene ring, similar as was found for non-phosphine containing CrFischer carbene complexes of the type $\left[(\mathrm{CO})_{5} \mathrm{Cr}=\mathrm{C}(\mathrm{X}) \mathrm{R}\right][26,45,46,47,48]$. The Mulliken spin plots of 1-4 further show that for both the first two oxidation processes involve a small amount of unpaired electron density, located on the CO groups. Negligible or no electron density on dppe ligands is observed for all reduction and oxidation processes.

\section{CV study}

In Figure 11 examples of the cyclic voltammograms (CVs) of 1-4 are presented. The CVs

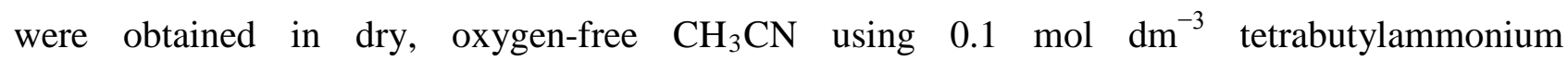
hexafluorophosphate $\left(\left[\left({ }^{n} \mathrm{Bu}\right)_{4} \mathrm{~N}\right]\left[\mathrm{PF}_{6}\right]\right.$ or $\left.\mathrm{TBAPF}_{6}\right)$ as supporting electrolyte, at a scan rate of 100 $\mathrm{mV} \mathrm{s}^{-1}$. The data are summarized in Table 5. Three main redox processes are observed in the solvent window: one reduction and two oxidation processes. The experimental results are in agreement with literature reports on related studies $[45,46,47,47,48,50,51,52$ and confirm the conclusions drawn from the DFT calculations that the reduction centre is located on the carbene carbon atom and the heteroarene substituent while the two oxidation processes is located on the $\mathrm{Cr}$ metal centre. No redox processes involving the heteroatom substituent or the dppe and CO ligands are observed in the potential window of the solvent, $\mathrm{CH}_{3} \mathrm{CN}$, used in this study. From the linear sweep voltammetry (LSV) presented in Figure 11 for $\mathbf{2}$ it is deduced that each of the three redox processes observed for $\mathbf{1 - 4}$, involves a one-electron process. 


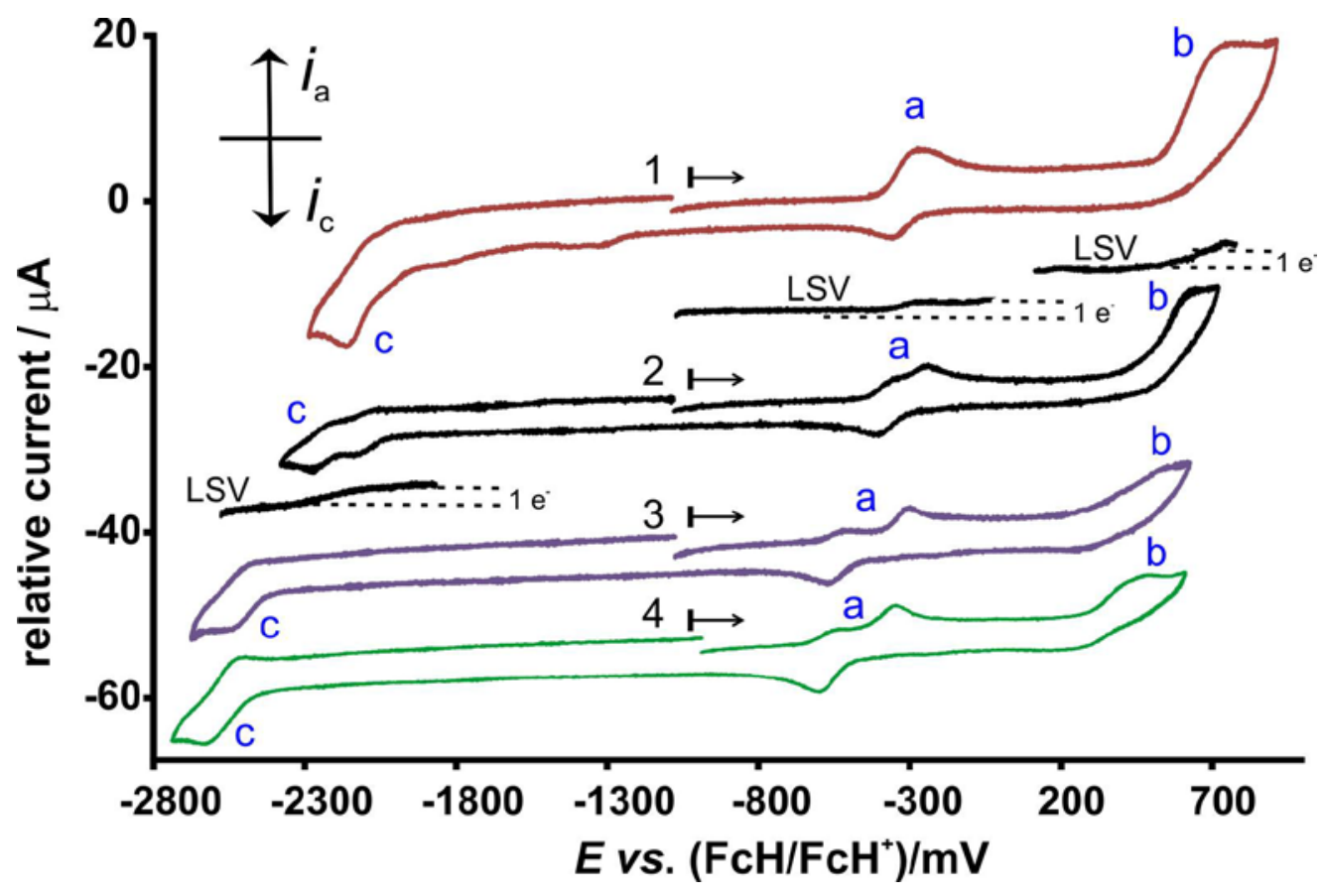

Figure 11 Cyclic voltammetric response of c.a. $0.5 \mathrm{mM}$ of 1-4 in $0.1 \mathrm{~mol} \mathrm{dm}{ }^{-3} \mathrm{TBAPF}_{6} / \mathrm{CH}_{3} \mathrm{CN}$ on a glassy carbon working electrode at $v=100 \mathrm{mV} \mathrm{s}^{-1}, \mathrm{~T}=20{ }^{\circ} \mathrm{C}$. Scan initiated in the positive direction at the arrow. The first and second oxidation process is indicated with a and b respectively, and the first reduction process is marked with c. The linear sweep voltammetry (LSV) of 2 is also shown.

\section{$\operatorname{Cr}(\mathrm{O})-\operatorname{Cr}(\mathrm{I})$ oxidation}

The oxidation process observed between -600 and $-250 \mathrm{mV}$ vs. $\mathrm{FcH} / \mathrm{FcH}^{+}$for 1-4, the first oxidation process observed after initiating the $\mathrm{CV}$ scan at $-1000 \mathrm{mV}$ vs. $\mathrm{FcH} / \mathrm{FcH}^{+}$, is ascribed to the oxidation of $\operatorname{Cr}(0)$ to $\operatorname{Cr}(\mathrm{I})$. Evaluation of the first oxidation process reveals that it consists of two oxidation peaks and one reduction peak. The two oxidation peaks are consistent with the oxidation of the mer and fac isomers of 1-4 being oxidized at a slightly different anodic peak potential, $E_{\mathrm{pa}}$. Assignment of a specific peak to a specific isomer (fac or mer) was based on experimental data and a DFT evaluation.

Firstly, DFT calculations were used to compare the relative stabilities of the HOMO's of the mer and fac isomers of 1-4. The energy of the HOMO of the fac isomer was found to be lower (more negative), implying that it will be more difficult to oxidize than the mer isomer, since more energy is needed to remove an electron from this orbital. It is thus concluded that the first oxidation peak correspond to the mer isomer, and the second peak to the fac isomer.

Secondly, experimentally it was more difficult to distinguish between the oxidation of the mer and fac isomers, due to the fast equilibrium between the two isomers in solution. However, by dissolving the pure mer isomer of $\mathbf{4}$ and recording a CV as fast as possible before the mer $\leftrightarrow$ fac 
equilibrium could be reached, we could illustrate that the first oxidation peak corresponds to the mer isomer, see Figure 12. With the second and further scans the mer $\leftrightarrow$ fac equilibrium was established. The mer $\leftrightarrow$ fac equilibrium for $\mathbf{4}$ is faster than the scan rate of $100 \mathrm{mV} \mathrm{s}^{-1}$.

Only one reduction peak, corresponding to the two oxidation peaks for the first oxidation of the set of isomers (fac and mer), is observed on the CV. This is ascribed to the reduction of the $\mathrm{mer}^{+}$ cation since (i) DFT calculations presented above showed that the $\mathrm{fac}^{+} \leftrightarrow \mathrm{mer}^{+}$equilibrium leads to more than $99.9 \% \mathrm{mer}^{+}$, (ii) the reduction peak of $\mathbf{4}$ corresponds to the position of the reduction peak of pure $\mathrm{mer}^{+}$of $\mathbf{4}$ in Figure 12 and (iii) the reduction peaks for all four complexes fall within 59-80 $\mathrm{mV}$ of the oxidation peak of the mer isomer of $\mathbf{1 - 4}$, as expected for a electrochemically reversible process [53]. The first oxidation process of related complexes $\left[(\mathrm{CO})_{5} \mathrm{Cr}=\mathrm{C}(\mathrm{OEt}) \mathrm{R}\right]$ with $\mathrm{R}$ = 2-thienyl (5) or 2-furyl (6) (Scheme 1), was also found to be electrochemically reversible $[45,46]$. The $\mathrm{fac}^{+} \rightarrow$ mer $^{+}$isomerization is much faster than the voltammetric time scale in 1-4, since the reduction of $\mathrm{fac}^{+}$could not be observed under any experimental conditions at any scan rate.

The first oxidation process of $\mathbf{1 - 4}$ is thus consistent with the electrochemical mechanism shown in Scheme 2. The proposed electrochemical scheme is supported by a similar electrochemical scheme proposed by Bond, Colton, and co-workers [8] on the fac and mer isomers of tricarbonyl chromium(I) phosphine, phosphite and bidentate phosphine complexes.

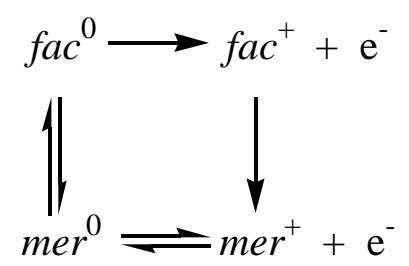

Scheme 2 The proposed mechanism for the electrochemical oxidation of the fac and mer isomers of 1-4

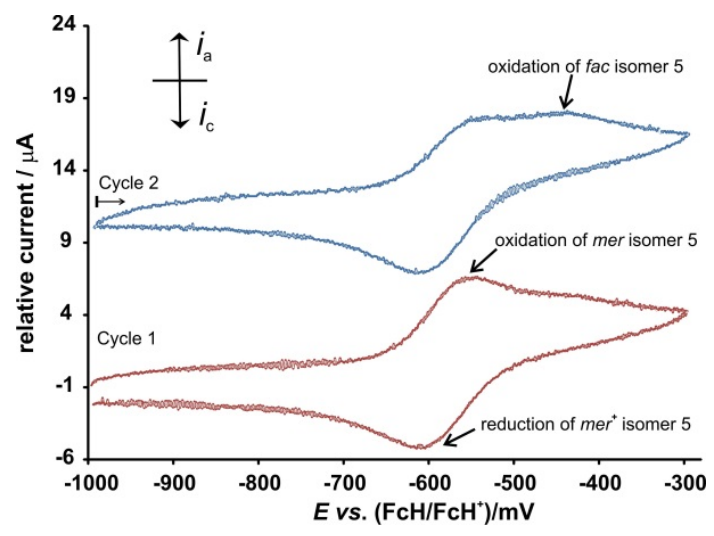


Figure 12 Cyclic voltammetric response of the mer isomer of $\mathbf{4}$, cycle 1 , directly after dissolving pure mer-4 and cycle 2 , the scan directly after cycle 1 . Both scans in $0.1 \mathrm{~mol} \mathrm{dm}^{-3} \mathrm{TBAPF}_{6} / \mathrm{CH}_{3} \mathrm{CN}$ on a glassy carbon working electrode at $v=100 \mathrm{mVs}^{-1}, \mathrm{~T}=20{ }^{\circ} \mathrm{C}$. Scan initiated in the positive direction at the arrow.

A few remarks relating to the oxidation of $\operatorname{Cr}(0)$ to $\operatorname{Cr}(\mathrm{I})$ for the individual complexes follows.

For 1, at low scan rates (50-500 $\left.\mathrm{mVs}^{-1}\right)$, a single chemically and electrochemically reversible one-electron oxidation response is observed at $c a$. $-0.270 \mathrm{vs}$. $\mathrm{FcH} / \mathrm{FcH}^{+}$. As the scan rate increases, however, the oxidation process broadens and subsequently splits into two responses, see Figure 13(a). Experimentally it was observed on the ${ }^{31} \mathrm{P}$ NMR of this complex that the mer isomer is the main isomer in solution. The electrochemically reversible one-electron oxidation response at low scan rates is thus assigned to the oxidation of the mer isomer of $\mathbf{1}$. The second oxidation process, observed at high scan rates $\left(>500 \mathrm{mVs}^{-1}\right)$, is an electrochemically irreversible one-electron oxidation response, which is interpreted as the oxidation of the fac isomer of $\mathbf{1}$. This implies that at low scan rates the mer $\leftrightarrow$ fac isomerization is faster than the scan rate and only the mer isomer is observed (all fac converted to mer during the oxidation process), but at high scan rates the mer $\leftrightarrow$ fac isomerization is slower than the scan rate, therefore the oxidation process of the fac isomer is also observed. Furthermore, when scanning four loops in a sequence directly after one another at a high scan rate $\left(500 \mathrm{mV} \mathrm{s}^{-1}\right)$, Figure 14, it seems that the amount of fac isomer being oxidized, gradually decreases from the first to the fourth cycle. This suggests that in the vicinity of the electrode the fac isomer is depleted since (i) there is no time for new fac isomers to diffuse to the electrode on the timescale of the $\mathrm{CV}$, and (ii) reduction of $\mathrm{mer}^{+}$leads to only mer being available for re-oxidation at the electrode surface. The CV results are thus consistent with complex $\mathbf{1}$ existing mainly as the mer isomer with a fac $\leftrightarrow$ mer isomerization in the order of medium scan rate (500 $\left.\mathrm{mVs}^{-1}\right)$.

For 2 at all scan rates two oxidation and one reduction peaks for the oxidation response at ca. -0.250 vs. $\mathrm{FcH} / \mathrm{FcH}^{+}$is observed, with the second oxidation peak intensifying at high scan rates. This result is consistent with a fast mer $\leftrightarrow$ fac isomerization rate is in the order of the scan rate at low scan rates and slower than the scan rate at high scan rates, see Figure 13 (b).

For 3 the fac isomer dominates at all scan rates (see e.g. CV in Figure 11). DFT calculations predict a 50:50\% distribution of the two isomers.

For 4 the mer:fac ratio at all scan rates seems constant. The mer $\leftrightarrow$ fac equilibrium in solution is reached within a minute after dissolving the pure mer isomer of $\mathbf{4}$, see Figure 12. 
$E^{0^{\prime}}$ values between -0.573 and $-0.314 \mathrm{~V}$ vs. $\mathrm{FcH} / \mathrm{FcH}^{+}$reported here for the first oxidation of the dppe-containing complexes $\left[(\mathrm{CO})_{3}(\mathrm{dppe}) \mathrm{Cr}=\mathrm{C}(\mathrm{X}) \mathrm{R}\right], \mathbf{1 - 4}$, is more as $500 \mathrm{mV}$ lower than $E^{0^{\prime}}$ reported for any on non-phosphine containing Cr-Fischer carbene complexes of the type $\left[(\mathrm{CO})_{5} \mathrm{Cr}=\mathrm{C}(\mathrm{X}) \mathrm{R}\right]$ with $\mathrm{X}=\mathrm{OEt}, \mathrm{NHBu}, \mathrm{NMe}_{3}$ or $\mathrm{N}\left(\mathrm{CH}_{2} \mathrm{Ph}\right)_{2}$ and $\mathrm{R}=$ phenyl, thienyl, furyl, NMe-pyrolle, $\mathrm{H}$ or $\mathrm{Me}$ with $E^{0^{\prime}}$ values ranging from +0.258 to $0.565 \mathrm{~V}$ vs. $\mathrm{FcH} / \mathrm{FcH}^{+}$ $[45,46,47,47,52]$. Since the oxidation centre for all these Fischer Cr-carbene complexes is mainly located on the Cr-metal centre, it is expected that the electronic influence of the dppe ligand directly attached to the $\mathrm{Cr}$ atom will be more pronounced than the influence of the different substituents on the carbene ligand. Phosphine is a weaker $\pi$-acceptor ligand than CO. The five (CO) groups attached to Cr will thus withdraw more electron density from the Cr-metal centre than three (CO) groups and the (dppe) ligand. With relatively more electron density on $\mathrm{Cr}$, oxidation of 1-4 is thus easier, at a lower potential.

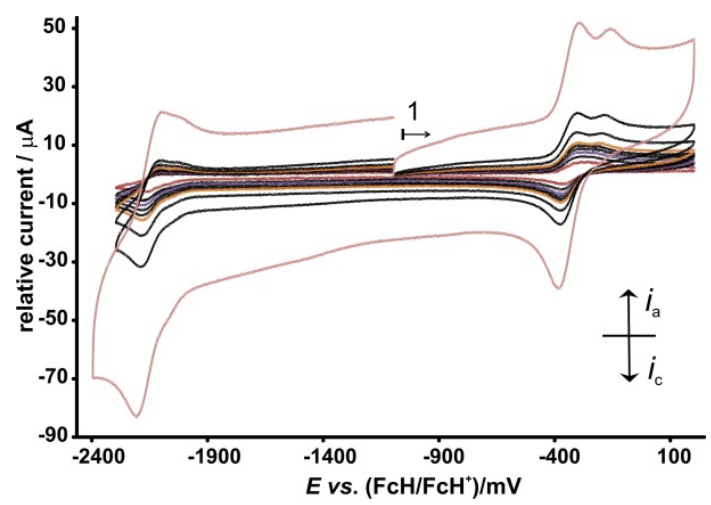

(a)

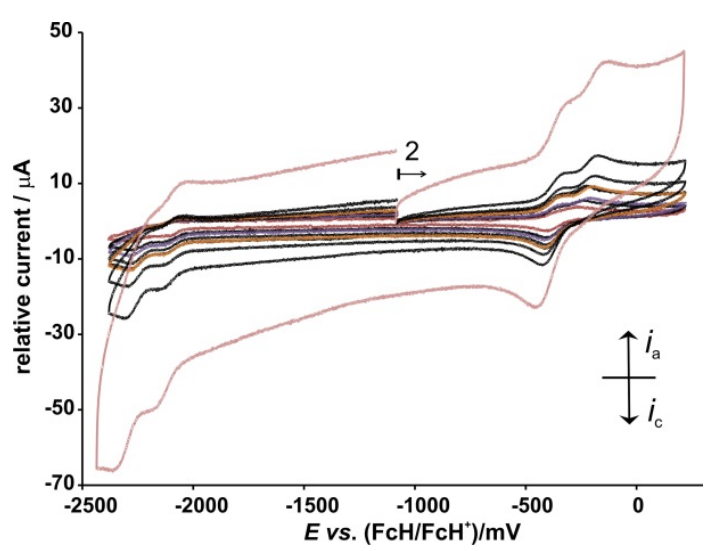

(b)

Figure 13 Cyclic voltammetric response of (a) 1 and (b) 2 in $0.1 \mathrm{~mol} \mathrm{dm}{ }^{-3} \mathrm{TBAPF}_{6} / \mathrm{CH}_{3} \mathrm{CN}$ on a glassy carbon working electrode at $v=50-5000 \mathrm{mV} \mathrm{s}^{-1}, \mathrm{~T}=20^{\circ} \mathrm{C}$. Scan initiated in the positive direction at the arrow.

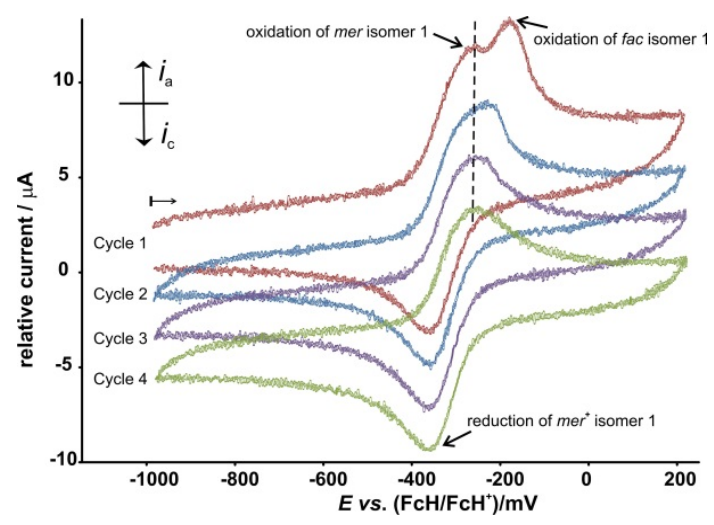


Figure 14 Four cyclic voltammetric responses, measured directly after each other, of complex 1 in $0.1 \mathrm{~mol} \mathrm{dm}^{-3} \mathrm{TBAPF}_{6} / \mathrm{CH}_{3} \mathrm{CN}$ on a glassy carbon working electrode at $v=500 \mathrm{mV} \mathrm{s}{ }^{-1}, \mathrm{~T}=20^{\circ} \mathrm{C}$. Scan initiated in the positive direction at the arrow.

\section{$\operatorname{Cr}(\mathrm{I})-\mathrm{Cr}(\mathrm{II})$ oxidation}

DFT calculations indicate that the second oxidation process observed in the potential window of the solvent, Figure 11, at positive potentials higher than $450 \mathrm{mV}$ vs. FcH/FcH ${ }^{+}$for 1-4, can be assigned to the $\operatorname{Cr}(\mathrm{I})-\mathrm{Cr}(\mathrm{II})$ oxidation process. This $\operatorname{Cr}(\mathrm{I})-\mathrm{Cr}(\mathrm{II})$ oxidation is, however, chemically as well as electrochemically irreversible. No reduction peak could be observed, even at scan rates of $5000 \mathrm{mV} \mathrm{s}^{-1}$. This second oxidation process involves a one-electron process, similar to the first oxidation of $\operatorname{Cr}(0)$ to $\operatorname{Cr}(\mathrm{I})$ (see LSV presented in Figure 11 for 2). The $\operatorname{Cr}(\mathrm{I}) \operatorname{Cr}(\mathrm{II})$ oxidation observed here for the dppe-containing complexes $\mathbf{1}-\mathbf{4}$, was previously observed and described for $\left[(\mathrm{CO})_{5} \mathrm{Cr}=\mathrm{C}(\mathrm{OEt}) \mathrm{Th}\right]$ [46] and three biscarbene Fischer carbene Cr complexes [45] in dichloromethane as solvent.

\section{The reduction process}

A reduction process is observed at a potential lower than $-2100 \mathrm{mV}$ vs. $\mathrm{FcH} / \mathrm{FcH}^{+}$for 1-4, see Figure 11. This reduction process is related to the reduction of the carbene ligand, forming a radical anion with electron density distributed over the heteroarene ring, see Figure 10. The reduction is chemically as well as electrochemically irreversible. Only for $\mathbf{1}$ and $\mathbf{4}$ a small reoxidation peak was observed at high scan rates, see Figure 13 for $\mathbf{1}$ and 2. It was not possible to unambiguously distinguish between the reduction of the mer and fac isomers of $\mathbf{1 - 4}$, although in some cases two reduction peaks near to each other was observed, e.g. see the reduction of 2 in Figure 13 (b).

Table 5 Experimental cyclic voltammetry and density functional theory calculated data for $(\mathrm{CO})_{3}(\mathrm{dppe}) \mathrm{Cr}=\mathrm{C}(\mathrm{X}) \mathrm{R}$ complexes $\mathbf{1}-\mathbf{4}, \mathrm{X}=\mathrm{OEt}(\mathbf{1}$ and $\mathbf{3})$ or NHCy (2 and 4). Cyclic voltammograms are obtained from $0.5 \mathrm{mmol} \mathrm{dm}{ }^{-3}$ solutions in $\mathrm{CH}_{3} \mathrm{CN}$ containing $0.1 \mathrm{~mol} \mathrm{dm}^{-3}$ $\mathrm{TBAPF}_{6}$ as supporting electrolyte on a glassy carbon-working electrode at a scan rate of $100 \mathrm{mV}$ $\mathrm{s}^{-1}$ and $20^{\circ} \mathrm{C}$. Experimental potentials are relative to the $\mathrm{FcH} / \mathrm{FCH}^{+}$couple. 


\begin{tabular}{|c|c|c|c|c|c|c|}
\hline \multirow[b]{3}{*}{ Complex } & \multicolumn{5}{|c|}{ Experimental } & \multirow[t]{2}{*}{ Calculated } \\
\hline & $1^{\text {st }}$ oxic & ion & & & $2^{\text {nd }}$ oxidation & \\
\hline & $E_{\mathrm{pa}}$ & $E_{\mathrm{pc}}$ & $\Delta E$ & $E^{0^{\prime}}$ & $E_{\mathrm{pa}}$ & $E_{\text {номо }}(\mathrm{eV})$ \\
\hline mer-1 & -0.275 & -0.353 & 0.078 & -0.314 & 1.233 & -4.816 \\
\hline$f a c-\mathbf{1}$ & - & - & - & - & - & -4.956 \\
\hline mer-2 & -0.356 & -0.410 & 0.054 & -0.383 & 0.625 & -4.738 \\
\hline$f a c-2$ & -0.235 & - & - & - & - & -4.907 \\
\hline mer-3 & -0.500 & -0.569 & 0.069 & -0.534 & 0.758 & -4.670 \\
\hline fac-3 & -0.306 & - & - & - & - & -4.741 \\
\hline mer-4 & -0.545 & -0.600 & 0.055 & -0.573 & 0.456 & -4.530 \\
\hline fac-4 & -0.368 & - & - & - & - & -4.679 \\
\hline
\end{tabular}

\section{Conclusion}

X-ray crystallography data showed unambiguously that both the mer and fac isomer of $\mathrm{Cr}$ carbenes of the type $\left[(\mathrm{CO})_{3}(\mathrm{dppe}) \mathrm{Cr}=\mathrm{C}(\mathrm{X}) \mathrm{R}\right]$ with $\mathrm{R}=$ 2-thienyl or 2-furyl and $\mathrm{X}=\mathrm{OEt}$ or NHCy exist in the solid state. In solution, experimental observation showed a fast mer $\leftrightarrow$ fac isomerization process. DFT calculations successfully demonstrated that MO arguments can be used to explain experimentally observed oxidation of the mer isomer at a slightly lower potential than the fac isomer. The observed $\mathrm{fac}^{+} \rightarrow \mathrm{mer}^{+}$isomerization process is in agreement with the DFT calculated relative stability of oxidized $\mathrm{fac}^{+}$and $\mathrm{mer}^{+}$complexes.

\section{Acknowledgements}

This work has received support from the Norwegian Supercomputing Program (NOTUR) through a grant of computer time (Grant No. NN4654K) (JC), the South African National Research Foundation (JC), the Central Research Fund of the University of the Free State, Bloemfontein (JC) and the University of Pretoria (ML and PHvR). The authors thank Dr. PBC Forbes (University of Pretoria) for some CHN analyses. 


\section{Supporting Information}

CCDC 946104, CCDC 946098, CCDC 946103, CCDC 946261, CCDC 946262, CCDC 946260 contain the supplementary crystallographic data for this paper. The optimized coordinates of the DFT calculations are given in the Supporting Information. 


\section{References}

(1) O.S. Mills, A.D. Redhouse, Chem. Commun. (1966) 814-815.

(2) H. Werner, H. Rascher, Inorg. Chim. Acta 2 (1968) 181-185.

(3) E.O. Fischer, R. Aumann, Chem. Ber. 102 (1969) 1495-1503.

(4) (a) E.O. Fischer, H. Fischer, Angew. Chem., Int. Ed. Engl. 11 (1972) 644-645;

(b) S. Maiorana, P. Seneci, T. Rossi, C. Baldoli, M. Ciraco, E. de Magistris, E. Licandro, A. Papagni, S. Provera, Tetrahedron Lett. 40 (1999) 3635-3638.

(5) E.O. Fischer, H. Fischer, Chem. Ber. 107 (1974) 657-672.

(6) M.D. Cooke, E.O. Fischer, J. Organomet. Chem. 56 (1973) 279-284.

(7) J. Barluenga, K. Muñiz, M. Tomás, A. Ballesteros, S. García-Granda, Organometallics 22 (2003) 17561760.

(8) (a) R.N. Bagchi, A.M. Bond, G. Brain, R. Colton, T.L.E. Henderson, J.E. Kevekordes, Organometallics 3 (1984) 4-9;

(b) A.M. Bond, R. Colton, J.E. Kevekordes, Inorg. Chem. 25 (1986) 749-756;

(c) A.M. Bond, R. Colton, S.W. Feldberg, P.J. Mahon, T. Whyte, Organometallics 10 (1991) 3320-3326.

(9) A.L. Rieger, P.H. Rieger, Organometallics 21 (2002) 5868-5873.

(10) B.S. Furniss, A.J. Hannaford, P.W.G. Smith, A.R. Tatchell, in: Vogel's Textbook of Practical Organic Chemistry, 5th ed, John Wiley \& Sons, New York, 1994, pp. 409.

(11) D.F Shriver, M.A. Drezdon, The manipulation of air sensitive compounds, 2nd ed, John Wiley and Sons, New York, 1986.

(12) G.H. Spies, R.J. Angelici, Organometallics 6 (1987) 1897-1903.

(13) H. Meerwein, Org. Synth. 46 (1966) 113-114.

(14) APEX2 (including SAINT and SADABS); Bruker AXS Inc., Madison, WI, 2012.

(15) G.M. Sheldrick, Acta Crystallogr. A, 64 (2008) 112-122.

(16) L.J. Farrugia, J. Appl. Crystallogr. 30 (1997) 565-565.

(17) D.T. Sawyer, J.L. Roberts (Jr), Experimental Electrochemistry for Chemists, Wiley, New York, 1974, p 54.

(18) D.H. Evans, K.M. O’Connell, R.A. Peterson, M.J. Kelly, J. Chem. Educ. 60 (1983) 290-293.

(19) G.A. Mabbott, J. Chem. Educ. 60 (1983) 697-701.

(20) G. Gritzner, J. Kuta, Pure Appl. Chem. 56 (1984) 461-466.

(21) A.J.L. Pombeiro, J. Organomet. Chem. 690 (2005) 6021-6040.

(22) A.D. Becke, Phys. Rev. A, 38 (1988) 3098-3100.

(23) C. Lee, W. Yang, R.G. Parr, Phys. Rev. B, 37 (1988) 785-789.

(24) M.J. Frisch, G.W. Trucks, H.B. Schlegel, G.E. Scuseria, M.A. Robb, J.R. Cheeseman, G. Scalmani, V. Barone, B. Mennucci, G.A. Petersson, H. Nakatsuji, M. Caricato, X. Li, H.P. Hratchian, A.F. Izmaylov, J. 
Bloino, G. Zheng, J.L. Sonnenberg, M. Hada, M. Ehara, K. Toyota, R. Fukuda, J. Hasegawa, M. Ishida, T. Nakajima, Y. Honda, O. Kitao, H. Nakai, T. Vreven, J.A. Montgomery (Jr), J.E. Peralta, F. Ogliaro, M. Bearpark, J.J. Heyd, E. Brothers, K.N. Kudin, V.N. Staroverov, T. Keith, R. Kobayashi, J. Normand, K. Raghavachari, A. Rendell, J.C. Burant, S.S. Iyengar, J. Tomasi, M. Cossi, N. Rega, J.M. Millam, M. Klene, J.E. Knox, J.B. Cross, V. Bakken, C. Adamo, J. Jaramillo, R. Gomperts, R.E. Stratmann, O. Yazyev, A.J. Austin, R. Cammi, C. Pomelli, J.W. Ochterski, R.L. Martin, K. Morokuma, V.G. Zakrzewski, G.A. Voth, P. Salvador, J.J. Dannenberg, S. Dapprich, A.D. Daniels, O. Farkas, J.B. Foresman, J.V. Ortiz, J. Cioslowski, D.J. Fox, Gaussian 09, Revision C.01, Gaussian Inc., Wallingford CT, 2010.

(25) (a) T.H. Dunning (Jr), P.J. Hay, Modern Theoretical Chemistry, Ed. H.F. Schaefer III, Vol. 3, Plenum, New York, 1976;

(b) P.J. Hay, W.R. Wadt, Chem. Phys. 82 (1985) 270-283;

(c) P.J. Hay, W.R. Wadt, J. Chem. Phys. 82 (1985) 284-298;

(d) P.J. Hay, W.R. Wadt, J. Chem. Phys. 82 (1985) 299-310.

(26) M. Landman, L. Renyuan, P.H. van Rooyen, J. Conradie, Electrochim. Acta (2013) DOI: 10.1016/j.electacta.2013.10.013.

(27) (a) M. Landman, J. Ramontja, M. van Staden, D.I. Bezuidenhout, P.H. van Rooyen, D.C. Liles, S. Lotz, Inorg. Chim. Acta 363 (2010) 705-717;

(b) M. Landman, H. Görls, S. Lotz, Eur. J. Inorg. Chem. (2001) 233-238;

(c) S. Lotz, M. Landman, H. Görls, C. Crause, H. Nienaber, A.J. Olivier, Z. Naturforsch. 62b (2007) 419426.

(28) J.A. Connor, E.M. Jones, J. Chem. Soc (A) 12 (1971) 1974-1979.

(29) C. Crause, H. Görls, S. Lotz, Dalton Trans. (2005) 1649-1657.

(30) (a) U. Klabunde, E.O. Fischer, J. Am. Chem. Soc. 89 (1967) 7141-7142;

(b) A. Yamashita, Tetrahedron Lett. 27 (1986) 5915-5918;

(c) C. Borel, L.S. Hegedus, S. Krebs, Y. Satoh, J. Am. Chem. Soc. 109 (1987) 1101-1105;

(d) J.F. Helling, S.C. Rennison, A. Merijan, J. Am. Chem. Soc. 89 (1967) 7140-7141.

(31) E.W. Reinheimer, K.A. Kantardjieff, S.R. Herron, C.G. Tisserat, J.A. Casalnuovo, J. Chem. Crystallogr. 33 (2003) 503-514.

(32) A. Arrieta, F. Cossío, I. Fernández, M. Gómez-Gallego, B. Lecea, M.J. Mancheño, M.A. Sierra, J. Am. Chem. Soc. 122 (2000) 11509-11510.

(33) R.J. Abrahams, J. Fischer, P. Loftus, Introduction to NMR Spectroscopy, Wiley, New York, 1988.

(34) E. Pretch, J. Seible, T. Clerc, W. Simon, Tables for Spectral Data for Structure Determination of Organic Compounds, 2nd ed, Springer-Verlag, Berlin and Heidelberg, 1989.

(35) S. Aoki, T. Fujimura, E.J. Nakamura, J. Am. Chem. Soc. 114 (1992) 2985-2990.

(36) W. Buchner, W.A. Schenk, Inorg. Chem. 23 (1984) 132-137.

(37) D.K. Mahapatra, D. Hazra, V.G. Puranik, A. Sarkar, J. Organomet. Chem. 689 (2004) 3501-3512. 
(38) S. Klapdohr, K.H. Dötz, W. Assenmacher, W. Hoffbauer, N. Hüsing, M. Nieger, J. Pfeiffer, M. Popall, U. Schubert, G. Trimmel, Chem. Eur. J. 6 (2000) 3006-3017.

(39) C.A. Merlic, D. Xu, S.I. Khan, Organometallics 11 (1992) 412-418.

(40) (a) U. Schubert, Coord. Chem. Rev. 55 (1984) 261-286;

(b) A. Hafner, L.S. Hegedus, G. de Week, B. Hawkins, K.H. Dötz, J. Chem. Soc. 110 (1988) 8413-8421;

(c) D.J. Cardin, B. Cetinkaya, M.F. Lappert, Chem. Rev. 72 (1972) 545-574;

(d) M.Y. Darensbourg, D.J. Darensbourg, Inorg. Chem. 9 (1970) 32-39.

(41) R. Streubel, S. Priemer, P.G. Jones, J. Organomet. Chem. 618 (2001) 423-434.

(42) D. Horng, C.-H. Ueng, J. Organomet. Chem. 505 (1995) 53-61.

(43) P.S. Braterman, Metal Carbonyl Spectra, 1st ed, Academic Press Inc., London, 1975.

(44) E.O. Fischer, K. Richter, Chem. Ber. 109 (1976) 2547-2557.

(45) B. van der Westhuizen, P.J. Swarts, I. Strydom, D.C. Liles, I, Fernández, J.C. Swarts, D.I. Bezuidenhout, Dalton Trans. 42 (2013) 5367-5378.

(46) B. van der Westhuizen, P.J. Swarts, L.M. van Jaarsveld, D.C. Liles, U. Siegert, J.C. Swarts, I. Fernández, D.I. Bezuidenhout, Inorg. Chem. 52 (2013) 6674-6684.

(47) R. Metelková, T. Tobrman, H. Kvapilová, I. Hoskovcová, J. Ludvík, Electrochim. Acta 82 (2012) 470477.

(48) I. Hoskovcová, J. Roháčová, D. Dvořák, T. Tobrman, S. Záliš, R. Zvěřinová, J. Ludvík, Electrochim. Acta 55 (2010) 8341-8351.

(49) T.A. Koopmans, Physica 1 (1933) 104-113.

(50) I. Hoskovcová, J. Roháčová, L. Meca, T. Tobrman, D. Dvořák, J. Ludvík, Electrochim. Acta 50 (2005) 4911-4915.

(51) I. Hoskovcová, R. Zvěřinová, J. Roháčová, D. Dvořák, T. Tobrman, S. Záliš, J. Ludvík, Electrochim. Acta 56 (2011) 6853-6859.

(52) C. Baldoli, P. Cerea, L. Falciola, C. Giannini, E. Licandro, S. Maiorana, P. Mussini, D. Perdicchia, J. Organomet. Chem. 690 (2005) 5777-5787.

(53) (a) M.J. Cook, I. Chambrier, G.F. White, E. Fourie, J.C. Swarts, Dalton Trans. (2009) 1136-1144

(b) E. Fourie, J.C. Swarts, I. Chambrier, M.J. Cook, Dalton Trans. (2009) 1145-1154.

(c) P.T. Kissinger. W.R. Heineman, J. Chem. Ed. 60 (1983) 702-706. 